NBER WORKING PAPER SERIES

\title{
INCENTIVES AND INVENTION IN UNIVERSITIES
}

\author{
Saul Lach \\ Mark Schankerman \\ Working Paper 9727 \\ http://www.nber.org/papers/w9727 \\ NATIONAL BUREAU OF ECONOMIC RESEARCH \\ 1050 Massachusetts Avenue \\ Cambridge, MA 02138 \\ May 2003
}

We are grateful to Adam Ja.e, Boyan Jovanovic, Jenny Lanjouw, Julia Shvets, Manuel Trajtenberg, Len Waverman, and Arvids Ziedonis for constructive comments on an earlier draft of this paper, and to Don Siegel for generous help with the AUTM data and other issues throughout the project. Alejandro Goren, Haim Mizrahi, and Anna Yosifun provided excellent research assistance. We would also like to thank Arnon Bentur, Director of the Samuel Neaman Institute for Advanced Studies in Science and Technology Policy at the Technion (Israel) for encouragement and financial support in this research project. The views expressed herein are those of the authors and not necessarily those of the National Bureau of Economic Research.

(C)2003 by Saul Lach and Mark Schankerman. All rights reserved. Short sections of text not to exceed two paragraphs, may be quoted without explicit permission provided that full credit including $(\mathrm{C}$ notice, is given to the source. 
Incentives and Invention in Universities

Saul Lach and Mark Schankerman

NBER Working Paper No. 9727

May 2003

JEL No.O31, O34, L3, L0

\section{$\underline{\text { ABSTRACT }}$}

We show that economic incentives affect the number and commercial value of inventions generated in universities. Using panel data for 102 U.S. universities during the period 1991-1999, we find that universities which give higher royalty shares to academic scientists generate more inventions and higher license income, controlling for other factors including university size, quality, research funding and technology licensing inputs. The incentive effects are much larger in private universities than in public ones. For private institutions there is a Laffer curve effect: raising the inventor's royalty share increases the license income retained by the university. The incentive effect appears to work both through the level of effort and sorting of academic scientists.

Saul Lach

Deparment of Economics

The Hebrew University

Jerusalem, Israel

and NBER

Saul.Lach@huji.ac.il
Mark Schankerman

Department of Economics, R.516

London School of Economics

Houghton Street

London WC2A 2AE, England

m.schankerman@1se.ac.uk 


\section{Introduction}

Universities are an important source of technical change. By the end of the 1990's, they accounted for about 50 percent of basic research and almost five percent of domestic patent grants in the U.S. (National Science Board, 2000). Academic research has had real effects on the economy by increasing the productivity of private sector $R \& D$ and the growth in total factor productivity (Jaffe, 1989; Adams, 1990). These benefits work through knowledge spillovers from academia to the rest of the economy, and through the licensing of university-owned inventions to private firms. ${ }^{1}$ This licensing activity facilitates the transfer of new scientific knowledge and the commercial development of these inventions by the private sector. Technology licensing activity has grown dramatically in the past two decades. ${ }^{2}$ The number of U.S. patents awards to university inventors rose from 500 in 1982 to more than 3,100 in 1998. The number of licenses executed on university inventions grew more than three-fold during the last decade, from 1,278 to 4,362 , and gross licensing revenues increased nearly seven-fold, from $\$ 186$ million to nearly $\$ 1.3$ billion.

Given the importance of university research for long term growth and productivity, it is critical to understand what drives academic research and technology licensing activity. Is it a purely intellectual pursuit, as many commentators claim, or do economic incentives influence how academic scientists structure their research activities? In one of the first papers to analyse theoretically the incentive effects of various award schemes to basic research at universities (e.g., NSF awards) and their economic efficiency, Lazear (1997) points out that "even research with direct marketability will not be undertaken at the appropriate rate unless the inventor is entitled to the full rents from the resulting advance".

\footnotetext{
${ }^{1}$ There is substantial evidence of R\&D spillovers (e.g., Jaffe, 1989; Jaffe and Trajtenberg, 2002; Adams, 1990, 2002). University research spillovers tend to be geographically localized as might be expected if direct knowledge transfers are important (Jaffe, Trajtenberg and Henderson, 1993; Audretsch and Stephan, 1996). There is also a growing empirical literature on university patenting and technology transfer (e.g., Henderson, Jaffe and Trajtenberg, 1998; Thursby and Kemp, 2002; Siegel, Waldman and Link, 2003) and university research productivity (Adams and Griliches, 1998).

${ }^{2}$ Part of this rapid growth in university innovation and licensing activity is due to the passage of the BayhDole Act of 1980 (Patent and Trademarks Amendments Act, PL 965-17) which gave universities the right to patent and a mandate to license discoveries made with federally sponsored research to the private sector. By the year 2000, nearly all American research universities had established, or expanded, technology licensing offices and introduced explicit intellectual property policies and royalty sharing arrangements for academic scientists.
} 
In this paper we take a first step in examining this issue by presenting econometric evidence on the role of economic incentives in shaping university research and licensing outcomes. Specifically, we examine how the cash flow rights from university inventions (the share of license royalties received by academic inventors) affect the licensing value of inventions generated by universities. In the United States, university intellectual property policies typically grant the university exclusive control rights over inventions. However, in all U.S. research universities the royalty income derived from licensing inventions is shared between the inventor and various parts of the university according to specified royalty sharing schedules. We show that there is substantial variation in these royalty sharing arrangements across U.S. research universities, and use this cross-sectional variation to estimate the effect of royalty sharing arrangements on license income.

We develop a simple model in which scientists allocate effort to produce more research projects, to improve the quality of each project, and to other responsibilities (e.g., teaching). Scientists attach private value to royalty income, publications and teaching, and face shadow prices of different types of effort set by the university. The model predicts that a rise in the inventor's share of royalties increases total revenues from licensed inventions. We test this prediction with university-level data from the Association of University Technology Managers, combined with information on the distribution of royalty shares, which we collected from the university websites.

This paper makes two main empirical contributions. First, we show that academic research and inventive activity respond to monetary incentives. This finding is important because it means that the design of intellectual property rights, and other forms of incentives, in academic institutions can have real effects on economic growth and productivity. Second, we show that the response to incentives is much stronger (and more significant) in private universities than in public ones. Controlling for a variety of other determinants, including university size, quality, R\&D funding and local demand conditions, private universities with higher royalty shares generate higher levels of license income. In private universities, the incentive effect is strong enough to produce a Laffer effect, where raising the inventor's royalty share would increase the license revenue actually retained by the university. We also show that technology licensing offices are more productive in private universities, suggesting that private institutions 
have more effective, commercially-oriented technology transfer activity.

We argue that this difference in TLO effectiveness (in terms of generating license income) can help explain the greater faculty responsiveness to royalty incentives in private universities. Because control rights over inventions reside with the university, the TLO effectively has exclusive rights to commercialise inventions disclosed by the faculty (unless expressly waived). As the "gatekeeper", the TLO's effectiveness at finding licensees, negotiating license agreements and other aspects of commercialising inventions, directly affects the monetary returns to the faculty scientist. Raising the royalty share should have a smaller effect on incentives if the faculty scientist anticipates that the TLO will be ineffective at commercialising her inventions. To examine this explanation we need to identify how public and private TLO's differ in ways that influence their effectiveness. For this purpose we developed a survey questionnaire for directors of TLO's in public and private universities. The survey indicates that TLO's in private universities are significantly more likely to use performance-based pay, to be much less constrained in their freedom of operation by state laws and regulations, and more likely to be focused on generating license income as compared to more "social" objectives such as promoting local and regional development. These findings provide reasons for the difference in effectiveness in public and private TLO's, and thereby a possible explanation for the private-public differential response to royalty sharing incentives.

The theoretical model serves to organize the empirical work, but it is very stylized. For example, we do not model the academic labor market and thus the equilibrium allocation of scientists across universities. As a consequence, the key empirical finding in this paper - that royalty incentives matter - may be due both to the effect of such incentives on research effort of individual scientists and to sorting behavior whereby universities offer higher royalty share to attract more productive scientists. Going beyond the model, in the empirical work we provide some evidence that both mechanisms may be at work, i.e., that the incentive effects work partly by inducing sorting of scientists across universities as well as by increasing scientists' effort levels.

We emphasise that this paper does not provide a normative analysis of technology licensing activity in universities. The trend toward greater commercialisation of university inventions may have both benefits and costs. What we do here is to show that the benefits to universities, 
in the form of license income, are strongly affected by how incentives are set. Of course, there may also be costs associated with greater emphasis on invention and licensing: for example, less "open science" in universities, a shift away from more basic towards more applied research, and so on. The public debate has focused heavily on such potential costs, but there is very little systematic evidence of these aspects to date. We do not address these costs in this paper.

The paper is organized as follows. Section 2 provides a detailed description of the data. Section 3 presents the analytical framework that underlies the empirical work. In Section 4 we present nonparametric evidence on the relationship between license income and inventor royalty shares. Section 5 presents the basic econometric results and their implications, including a test of whether incentives work both through effort and sorting of faculty. We also examine whether the incentive effect works mainly on the quantity or quality of inventions. Section 6 provides robustness checks. Brief concluding remarks follow.

\section{Data Description}

The data assembled for this project came from three main sources: 1) the Annual Licensing Surveys for the years 1991-1999 published by the Association of University Technology Managers (AUTM), 2) the 1993 National Survey of Graduate Faculty conducted by the National Research Council (NRC), and 3) royalty sharing arrangements downloaded from technology licensing offices' websites. Definitions of the main variables and a description of the sample selection process are provided in a data Appendix.

The AUTM surveys provide information on licensing income, number of licenses, number of inventions reported to the TLO (invention disclosures), characteristics of the technology licensing office (TLO), and R\&D funding from external sources in universities, medical research institutes and patent management firms.

In the empirical analysis we need to control for differences across universities in faculty size and scholarly quality. Data on the size and quality of university doctoral programs were obtained from the 1993 NRC survey. For each university we used data on doctoral programs in twenty-three different fields of science. ${ }^{3}$ We measure university size as the total number of

\footnotetext{
${ }^{3}$ See the Appendix for a list of these fields. Further details on the classification can be found in Appendices $\mathrm{K}, \mathrm{L}$ and $\mathrm{N}$ in Goldberger et al. (1995).
} 
faculty members in the doctoral programs in these twenty-three fields. We use three measures of university quality: the number of citations per faculty, the number of publications per faculty, and a scholarly quality rating score between zero ("not sufficient for doctoral education") and five ("distinguished"). The NRC survey reports these variables at the program level but we aggregated them to the university level using faculty size weights. The size and quality variables do not vary over time.

Table 1 reports descriptive statistics for the 102 universities in our sample. The universities in our sample account for 56.1 percent of the total license income reported by AUTM in 1995, and 68.1 percent of the total in 1999. The sample universities generate 3.4 million dollars of licensing income per year, on average. Not surprisingly, this income is unevenly distributed across universities: the median licensing income is just $\$ 620,000$, but, the top universities earn over $\$ 40$ million per year while others have zero licensing income. Normalizing by the number of active licenses (row 2) does not eliminate this variation. Half of the universities have licenses generating less than $\$ 17,000$ on average, while the top 5 percent of the universities have licenses generating over $\$ 111,000$. The same uneven pattern is observed in the number of invention disclosures, although some of the variance in disclosures is related to faculty size (rows 3 and 4). In sum, the distributions of licensing value and the number of invention disclosures are very right-skewed: only a few universities produce large numbers of inventions, and only a few inventions are very valuable.

The three measures for university quality are reported in rows 6-8. Citations per faculty captures both the quantity and quality of publications and exhibits the highest dispersion across universities. Technology licensing offices at most universities are quite small, with a mean of about three full-time professionals. The average age of TLO's in 1999 was 16, reflecting the stimulus to commercialize university inventions given by the 1980 Bayh-Dole Act.

Our third source of data was information on the distribution of licensing income between faculty scientists and the university, i.e., on the arrangements for sharing the royalties generated by the licensed inventions. This information was downloaded from the websites of individual technology licensing offices during the summer of 2001 and it constitutes the novel aspect of our data.

The intellectual property policies of the universities usually state that a percentage of 
the net income received by the university from licensing an invention is retained by the inventor and the rest is allocated to the inventor's lab, department, college and to the university. The criterion we used for identifying the inventor share is that the inventor must gain either cash flow rights or direct control rights over the income. Thus, when the university IP policy states that the share accruing to the lab was under the control of the inventor, we added it to the inventor's share, but otherwise we did not. We call this the inventor's royalty share.

The observed royalty shares were those in effect (and posted) in 2001. Because we will examine the effect of these royalty shares on inventive outcomes, we were concerned by our inability to identify any changes that might have occurred in these shares during the 1991-1999 period (when outcomes measures are available). We sent a question by e-mail about this to the TLO's in the sample and found that 70 percent of the universities did not change their royalty distribution during 1991-1999. Thus, for most universities the royalty sharing rates remained unchanged during the sample period. In fact, in many cases the arrangements were set in the early 1980s and never changed. ${ }^{4}$

In 58 universities the inventor royalty share is a fixed percentage of the license income generated by an invention (we call these linear royalty schedules). Interestingly, in the other 44 universities these royalty shares vary with the level of license income generated by an invention (we call these non-linear royalty schedules). Because the income intervals differ across universities, we divided the license income into seven intervals based on the most frequently observed structure (in US\$): 0-10,000, 10,000-50,000, 50,000-100,000, 100,000-300,000, 300,000-0.5 million, 0.5-1.0 million, and over 1 million. ${ }^{5}$

Table 2 presents the main features of the royalty share data. The mean inventor's share is 41 percent among the 58 universities using linear royalty schedules, but there is substantial cross-sectional variation. About 25 percent of these universities have royalty shares lower than a third, while the top 25 percent have royalty shares larger than 50 percent. The royalty shares

\footnotetext{
${ }^{4}$ In total, 53 universities responded to this query. Of the 16 that reported a change in royalty shares during 1991-99, only 11 reported the pre- and post-change royalty sharing agreements. In these cases, we updated the data according to the information received. In the remaining 5 universities, we used the shares reported in 2001.

${ }^{5}$ In the many cases where our selected interval did not correspond to the interval chosen by the university, we recomputed royalty shares with the correct weights. For example, if a university reports a 50 percent share for income less than 5,000 and 40 percent share for income above 5,000, this would appear as an 45 percent share in the first interval $(0-10,000)$ and an 40 percent share in all the remaining intervals.
} 
in the 44 universities with non-linear schedules display even larger cross-sectional variability within each license income interval. For these universities we compute an expected royalty share by weighting the average share in each income interval by the probability of observing license income in that interval. These probabilities were estimated non-parametrically from the distribution of license incomes over all years in the AUTM sample. Let $v_{i t}$ denote license income per invention disclosure in university $i$ in year $t$. There are 723 different values for $v$ in the sample. We first estimated the density $f\left(v_{i t}\right)$ by kernel methods at these values. We then computed an average royalty share for each value of $v, \bar{s}(v)$, using the royalty schedule for each university, taking into account the varying marginal royalty rates. ${ }^{6}$ The expected royalty share is then

$$
s \equiv \Sigma_{v} \bar{s}(v) \widehat{f}(v)
$$

Of course, when the royalty schedule is linear, the expected royalty rate is simply the reported (constant) share. ${ }^{7}$

The estimated density function of $v$ shows the extreme dispersion and skewness of license income per invention disclosure (see Figure 1). ${ }^{8}$ Nearly all of the weight is on the first two income intervals -50.2 percent in the $0-\$ 10,000$ interval and 46.1 in the $\$ 10,000-\$ 50,000$ bracket. This feature shows that taking a simple average of all sharing rates in a nonlinear schedule would be inappropriate. In fact, for practical purposes a good approximation is simply to average the first two sharing rates.

Using the estimated $f(v)^{\prime} s$, the expected royalty share averages to 51 percent across universities, higher than the average royalty share in the universities having linear schedules (Table 2). The expected inventor's share also exhibits a large variability ranging from 20 to

\footnotetext{
${ }^{6}$ For example, with three marginal rates the average share is

$$
\bar{s}(v)=\frac{s_{1} v}{v} I\left(0 \leq v \leq v_{1}\right)+\frac{s_{1} v_{1}+s_{2}\left(v-v_{1}\right)}{v} I\left(v_{1}<v \leq v_{2}\right)+\frac{s_{1} v_{1}+s_{2} v_{2}+s_{3}\left(v-v_{2}\right) I\left(v>v_{2}\right)}{v}
$$

where $I(\cdot)$ is an indicator function.

${ }^{7}$ Two other points should be noted. First, we also used yearly license income divided by the cumulative number of active licenses as a measure of $v$ and obtained essentially the same estimates of $s$. The two estimates differ by at most 1.7 percentage points, and the average difference is 0.7 percentage points. We normalized by disclosures because data on cumulative licenses is available only since 1995 resulting in a smaller number of observations. Second, one might want to estimate separate density functions for sub-categories of the pooled data-e.g., for different technology fields-but we do not have enough data to do this successfully.
}

${ }^{8}$ Such skewness is typical of distributions of the returns to innovation (Schankerman, 1998). 
97 percent. This remarkable variability across universities is clearly seen in Figure 2, where the histogram and a nonparametric estimate of the density of the expected royalty share are displayed.

Another striking feature of Table 2 is that inventor royalty shares are either constant or decline in the level of license income per invention- royalty retention is regressive (equivalently, the university 'tax' on inventors is progressive). On average, they start at 53 percent in the lowest interval and decline to 30 percent for inventions generating over $\$ 1$ million. This feature holds in every quartile of the cross-sectional distribution and, in fact, it holds for every university in our sample with non-linear royalty schedules. ${ }^{9}$

In a first attempt to understand the determinants of the variation in royalty shares across universities, we split the sample into four quartiles defined by university characteristics (e.g., faculty size) and computed the mean royalty share in each quartile. Table 3 summarises the results. Royalty shares are not related to faculty size, the number of citations per faculty, or the size of the TLO office (measured by the number of TLO professionals per faculty). In fact, the hypothesis that the mean royalty rate is the same across the four quartiles of the distribution of each characteristic cannot be rejected (last row). Apparently there is no significant correlation between royalty shares and a variety of university characteristics, taken individually.

These simple bivariate comparisons also hold in a regression context. Table 4 presents the results from regressing the royalty shares on the above characteristics and additional controls, using the time-averages of the variables (the between-university regression). In the first column the royalty share is regressed on faculty size, and the three proxies for university quality. None of these regressors is significant, nor is the regression as a whole ( $\mathrm{p}$-value $=0.25)$. Adding the scientific composition of the faculty-the shares of total faculty in each of six main science

\footnotetext{
${ }^{9}$ Regressive royalty schedules give inventors an incentive to discover many small-valued inventions rather than a single valuable one, which seems odd if universities prefer quality to quantity of inventions. However, it may be possible to rationalise such schedules by appealing to optimal taxation theory. That literature can generate progressive tax schedules when there is uncertainty to effort. The intuition is that, when high income ex post is largely due to a favorable resolution of uncertainty, the incentive cost of higher marginal taxation is lower (Tuomala, 1990). This argument may also apply to research effort, if the quality of the project is unknown ex ante to the scientist. However, if the inventor can distinguish between low and high quality projects in making effort decisions, then optimal incentives should involve a progressive inventor royalty to compensate for the higher marginal cost of producing high-valued inventions. Of course, 'fairness' considerations may also play a role in how universities share royalties.
} 
fields ${ }^{10}$-does not have a significant effect on inventor's shares (column 2). This is interesting, since academic scientists usually sit on the governance committees that set these rates.

In column 3 we add two features of the TLO: size, measured by the number of full time professionals, and experience, measured by its (average) age. There is some evidence that royalty shares are negatively related to the age of the TLO. Whatever the explanation for this, we should not put too much emphasis on this finding because the quantitative effect is very small. A one-year increase in TLO age is associated with a decline in royalty share of a third of a percentage point.

Adding controls for the level of $\mathrm{R} \& \mathrm{D}$ funding for and the average salary at the university level do not alter these results (column 4). Interestingly, the average salary is negatively correlated with the expected royalty share: the point estimate implies that an additional thousand dollars reduces the share by a quarter of a percentage point. This suggests a trade-off between high-powered incentives and salaries. The average salary coefficient, however, is not significantly different from zero. ${ }^{11}$

The private university dummy is also not significant. The average inventor royalty shares for public and private universities are almost the same: 46 and 44 percent, respectively, and not statistically different $(\mathrm{p}$-value $=0.48)$. Moreover, there are no significant differences in the empirical distribution of royalty share in private and public universities.

To summarize, the two salient features of observed royalty shares are their variability across universities and their regressiveness in the level of license income. Moreover, we have shown that inventors' expected royalty shares are only weakly related to observed university characteristics. This raises the question of whether existing royalty distribution schemes have been set in any systematic or strategic way. Putting this aside, one may be tempted to conclude that these shares do not matter for academic innovation and technology licensing performance. Is royalty sharing a purely distributive matter, or does it affect the "size of the pie", i.e., innovative performance? In this paper we take the royalty shares as given and exploit their

\footnotetext{
${ }^{10}$ See the Appendix for definitions.

${ }^{11}$ This estimate is likely to be biased towards zero due to measurement error in the average salary. We use a university-based average of salaries, but we would really like to have the average salary of faculty in hard science departments.
} 
cross-sectional variation to identify whether they have an effect on inventive activity.

\section{Analytical Framework}

There are two basic channels through which royalty incentives to faculty can affect inventive outcomes in universities. First, a higher royalty share can induce faculty to devote greater effort to more commercially-oriented research than to other types of research, teaching or administrative activities. We call this the effort channel. Second, a higher royalty share can attract more productive and commercially-oriented researchers in a world where faculty differs in their research productivities. This results in a reallocation or sorting of more productive faculty into universities with stronger royalty incentives. We call this the sorting channel. Of course, both mechanisms may be operating at the same time.

Here we develop the effort model in some detail in order to organize the empirical work. With the available university-level data, both the effort and sorting mechanisms generate the same prediction and thus may appear to be observationally equivalent: higher royalty shares lead to higher inventive output (e.g., licensing income) in both models. To differentiate properly between the two models, we would need data on the flows of faculty and their quality across universities, which to the best of our knowledge are not available in a systematic form. Nevertheless, in Section 5.5 we develop one simple implication of the sorting model which can be tested with our data. A more complete assessment of the effort and sorting effects is important because their policy implications are very different. The effort model implies that strengthening royalty incentives would increase aggregate inventive output, whereas a pure sorting model would imply that this would only redistribute inventive output across universities. ${ }^{12}$

We assume that academic scientists use a fixed amount of effort (work time) $T$ to perform three tasks: starting new research projects, improving their quality, and teaching/administrative activities. The number of inventions $n$ generated by a researcher depends on the scientist's effort, $z$, devoted to starting new projects, given by $n=n(z)$. This invention function satisfies the usual properties $n^{\prime}(z) \geq 0, n^{\prime \prime}(z) \leq 0$ and $n(0)>0$. Each invention has the same initial quality $v_{0}$. By investing research effort $q$ into a (single) project, the researcher can transform

\footnotetext{
${ }^{12}$ Unless there are large externalities (spillovers) from concentrating more productive faculty in one location.
} 
it into an invention potentially worth

$$
v(q)=v_{0} \psi(q) \varepsilon
$$

where $\psi(q) \geqslant 1$ is increasing and concave and $\varepsilon$ is a multiplicative shock independent of $q$, with mean value normalized to one and distribution function $G$. The shock $\varepsilon$ is observed after the two types of effort are invested. As there are no ex-ante differences among the $n$ inventions, the inventor invests the same level of effort $q$ in each of them. ${ }^{13}$

We assume that the effort constraint is binding so that the remaining effort, $T-z-n(z) q$, is spent in teaching and administrative activities. The research activities generate $n$ inventions with average commercial potential $v$, as well as academic publications. Academic publications depend on the number of projects $n$ and their quality $v$, so expected publications depend ultimately on $z$ and $q, p(z, q)$. However, the partial effects of quantity and quality effort on publications do not need to be positive if there is a conflict between commercially-oriented and academic research.

We assume that all inventions are disclosed to the TLO and that the TLO then chooses whether or not to license the invention depending on the observed value of the idea. The TLO licenses an invention if expected license income covers the fixed cost of licensing, which includes finding suitable licensees, negotiating terms, and enforcing contracts. We model the selection rule as follows: license the invention if $v>\underline{v}$. This implies that, given effort $q$, an invention is licensed if $\varepsilon>\frac{v}{v_{0} \psi(q)}$, so a proportion $1-G\left(\frac{\underline{v}}{v_{0} \psi(q)}\right)$ of all inventions is licensed. ${ }^{14}$

The TLO is in charge of compiling a list of all inventions made by faculty and licensing them to private firms. If the TLO licenses the invention, it earns revenue $\theta v$, where $0<\theta \leq$ 1 reflects the effectiveness of the TLO's licensing activities. The amount $v$ is the maximal potential income derived from licensing the invention, which should reflect the most favorable

\footnotetext{
${ }^{13}$ An equivalent formulation would be to allow the initial value of the idea to be random and unknown to the researcher when the decision on effort $q$ is made. We need to have some form of uncertainty in the model because otherwise the scientist would either set $q=0$ or set $q$ at a level to ensure that any developed idea would pass the TLO selection rule (see below in the text). But this is not consistent with the data: the ratio of licenses executed to invention disclosures in a given year is about 30 percent, on average.

${ }^{14}$ This way of specifiying the TLO licensing decision is consistent with new survey data we gathered from TLOs, described briefly in Section 5.3. This was the licensing criterion most frequently cited by respondents. On the theoretical level, Macho-Stadler, Perez-Castillo and Veugelers (2004) develop a model in which the TLO has an incentive to shelve some projects, i.e., not commercialize them, because of reputation effects.
} 
license fee and royalties schedule among all the potential licensees. The actual license income depends on how good the TLO is at identifying the best match and negotiating the best agreement. ${ }^{15}$ If the invention is not licensed, it earns zero revenue.

The expected license revenues generated by inputs $(z, q)$ are

$$
r(z, q)=\theta n(z) v_{0} \psi(q) \int_{\frac{\underline{v}}{v_{0} \psi(q)}}^{\infty} \varepsilon d G(\varepsilon)
$$

When $n^{\prime}(z)>0$ we have that $\frac{\partial r}{\partial z}>0$, and when $\psi^{\prime}(q)>0$, we have $\frac{\partial r}{\partial q}>0$. Notice that quality effort has two effects: it raises the value of the idea and it increases the probability that it will be licensed by the TLO.

The academic scientist derives utility from research and from time spent in teaching. The utility from research is composed of the expected monetary benefit accruing to the scientist's inventions (royalty income, sr) and from publications,

$$
U(z, q)=V(\operatorname{sr}(z, q), p(z, q), T-z-n(z) q)
$$

where $p$ denotes expected publications. ${ }^{16}$

We assume that $U(z, q)$ is concave. Of course, we require that $U$ be increasing in some region of $(z, q)$ but it is quite possible that, because of diminishing returns, at some point investing more effort in research decreases $U$ because of the disutilities attached to less teaching and possibly fewer academic publications.

We assume that the costs associated with research effort, $C(z, q)$, are convex. The marginal costs $C_{z}$ and $C_{q}$ represent the opportunity cost of a unit of effort invested in starting more projects to the inventor (resp. investment in quality per project). These parameters reflect the university's valuation of the two types of research effort and teaching time. The university control these shadow prices by setting promotion criteria and other rewards. ${ }^{17}$ The faculty scientist's objective is to choose $(z, q)$ to maximize

\footnotetext{
${ }^{15}$ Jensen and Thursby (2001) analyse optimal contract design for university technology transfer.

${ }^{16}$ In what follows we assume that $s$ does not depend on $v$ since this is not central to the argument.

${ }^{17}$ We view this specification as a reduced form of some underlying model of the academic labour market. The shadow prices imposed by the university presumably reflect the marginal products of research efforts $(z, q)$ in terms of the university's objectives. These may differ from the utility value attached by the scientist if their objectives are not well aligned. Conflict of interest provisions, which are commonly found in university intellectual property policies, suggest that problems of alignment do exist.
} 


$$
\pi(z, q) \equiv U(z, q)-C(z, q)
$$

The first order conditions at an interior solution are

$$
\begin{aligned}
s V_{r} \frac{\partial r}{\partial z}+V_{p} \frac{\partial p}{\partial z}-V_{t}\left(1+n^{\prime}(z) q\right) & =C_{z} \\
s V_{r} \frac{\partial r}{\partial q}+V_{p} \frac{\partial p}{\partial q}-V_{t} n(z) & =C_{q}
\end{aligned}
$$

where $V_{j}(j=r, p, t)$ is the marginal utility from license income, publications and teaching, respectively.

At the optimum, the scientist balances the marginal utility associated with more research - which itself depends on the various positive and negative contributions of the different activities - with its marginal cost. To ensure that optimal research effort levels are positive, we require that $\pi(z, q)$ is increasing at $(0,0)$.

The important point is that, provided the scientist cares about the monetary returns from inventions, $V_{r}>0$, the royalty share affects effort because it determines the scientist's expected income. We have:

Proposition 1 Provided that $V_{r}>0$ and $\pi_{z q}$ is not too negative, optimal research effort levels are rising in the inventor's royalty share $s^{18}$

The scientist's expected income is also determined by the effectiveness of the TLO in exploiting the potential value of the invention $v$. For this reason, TLO effectiveness should also influence research effort. In our modelling approach, the index of TLO's efficiency at performing this task, $\theta$, enters the problem in the same way $s$ does. Incentives can be increased either by distributing a larger share of the invention value to faculty or by realizing a higher fraction of the full potential of these inventions. Thus, $\theta$ affects research efforts $(z, q)$ in the same way as $s$.

In short, the model implies that, under certain conditions, research effort $z$ and $q$ depend positively on $(s, \theta)$. This is the implication we would like to to test empirically. Unfortunately,

\footnotetext{
${ }^{18}$ Standard comparative statics give $\frac{d z}{d s}=\frac{\pi_{q s} \pi_{z q}-\pi_{z s} \pi_{q q}}{A}$ and $\frac{d q}{d s}=\frac{\pi_{z s} \pi_{z q}-\pi_{q s} \pi_{z z}}{A}$, where $\pi_{i j}$ denotes a cross partial and $A=\pi_{z z} \pi_{q q}-\pi_{z q}^{2}>0$ by the second order conditions. But $\pi_{z s}=V_{r} \frac{\partial r}{\partial z}>0$ and $\pi_{q s}=V_{r} \frac{\partial r}{\partial q}>0$. A rise in $s$ raises the marginal utility of $z$ and $q$ due to the multiplicative specification "sr $(z, q)$ ". Thus $\frac{d z}{d s}>0$ and $\frac{d q}{d s}>0$ provided $\pi_{z q}$ is not "too negative".
} 
data on research efforts are not available. However, we observe license income which, according to the model, reflects these efforts. In fact, since revenue per faculty, $r(z, q)$, increases with $z$ and $q$ the model implies that $r(z, q)$ also rises with $s$.

Expected licensing revenues at the university equals (1) multiplied by the number of university faculty, $F$ :

$$
R=r F=\theta v_{0} \psi(q(s, \theta)) n(z(s, \theta)) F \int_{\frac{v}{v_{0} \psi(q(z, \theta))}}^{\infty} \varepsilon d G(\varepsilon)
$$

Because $s$ increases both $z$ and $q$, and thus $r$, total university expected license income also increases with $s$. This is the implication we set out to test with the data.

To obtain our estimating equation, we transform (3) into logs and approximate the nonlinear terms involving $s$ and $\theta$ by $\delta s+\widetilde{\beta} \log \theta$. This yields

$$
\begin{aligned}
\log R & =\log \theta+\log v_{0}+\log F+\log \left(\psi(q(s, \theta)) n(z(s, \theta)) \int_{\frac{v}{v_{0} \psi(q(z, \theta))}}^{\infty} \varepsilon d G(\varepsilon)\right) \\
& \approx \delta s+\widetilde{\beta} \log \theta+\log v_{0}+\log F+\text { terms involving } G, \underline{v} \text { and } v_{0}
\end{aligned}
$$

We do not observe $\theta$ directly. We use a set of observed variables $x$ to proxy for $\log \theta$ : $\widetilde{\beta} \log \theta=\beta \pi+\eta, E(\eta \mid x)=0$, and collapse all the other factors affecting license revenues into a vector $\omega$. This results in the estimating equation

$$
\log R=\delta s+x \beta+\omega \gamma+u
$$

where $u$ captures the deviation of $\log R$ from its expected value, as well as functional form approximation and proxying errors. ${ }^{19}$

The vector $\omega$ includes variables that account for differences in license revenues across universities, other than through differences in $s$ and $x$, including: (log) faculty size, for which we expect an elasticity of about unity, and the number of citations per faculty to account for initial quality $\left(v_{0}\right)$, which should also have a positive effect because inventions are more valuable and are more likely to be licensed the higher is $v_{0}$. Differences in the distribution of

\footnotetext{
${ }^{19}$ We now abuse notation by denoting observed license revenues by $R$.
} 
quality shocks, $G$, across universities are captured by differences in their research orientation, measured by the shares of faculty employed in each of six science fields (see Appendix), and by the amount of R\&D funding available to the university. These variables are also part of $\omega$.

We emphasize that the estimating equation (5) is not an invention production function. The latter cannot be estimated because we do not observe the inputs $z$ and $q$. Rather, equation (5) is interpreted as a reduced form equation specifying the (exogenous) drivers of licensing income. These drivers, $s$ and $\theta$, operate through the unobserved research effort levels and the TLO licensing behavior. This last point is important. The observed data are not a random sample of all inventions generated by the university faculty. The scientist selects which inventions are worth reporting and the TLO selects which inventions are worth marketing. We have taken only the TLO selection into account in the modelling framework, i.e., we conditioned on disclosed inventions. As equation (3) makes clear, the estimated incentives effects include these TLO selection effects. ${ }^{20}$

We assume that the royalty share is exogenous in equation (5) and estimate its parameters by ordinary least squares. We discuss the validity of this assumption in Section 5.2. The data used to estimate equation (5) consist of an unbalanced panel of 102 universities over 9 years, 1991-1999 (see the Appendix for details). However, panel data estimation methods that allow for a correlation between the royalty share and unobserved, time-invariant determinants of license revenues - such as fixed effects or first differences - are of limited use here because the royalty share does not vary over time in 90 percent of the observations. We rely on cross-sectional variation to identify the incentive effect on license income. We use a consistent estimator of the covariance matrix that allows for arbitrary heteroskedasticity and serial correlation within universities, but we assume that disturbances are uncorrelated across universities; i.e., standard errors are clustered at the university level. ${ }^{21}$

\footnotetext{
${ }^{20}$ The estimated incentive effect will also include any effect of royalty shares on the willingness of faculty to report inventions to the TLO. Such nonreporting bias can easily be incorporated into the model, but since we cannot identify the separate selection effects we refrain from doing so.

${ }^{21}$ There is one estimation issue that arises from the computation of the expected royalty share for universities with nonlinear royalty schedules. The density estimates used to compute the expected royalty share are based on the observed unconditional distribution of license income per disclosure. The model, however, says that the distribution of license income per disclosure depends on the control variables $s, x$ and $\omega$. In order to account for this, we used an iterative procedure whereby the residuals from an initial license income per disclosure (i.e., $v$ ) regression are used to recompute the kernel density estimates and the expected royalty shares. We found that
} 


\section{Nonparametric Evidence}

Because we showed that royalty shares, $s$, are mostly unrelated to other university observables, we are arguably justified in examining the expectation of license revenue conditional on $s$ and interpreting this relationship as causal. The advantage of abstracting from other determinants of license income is that we can easily estimate this conditional expectation non-parametrically, i.e., we can let the data determine the shape of the conditional expectation function, rather than imposing a linear or log-linear form (as in (5)). We estimate the expectation of license income per faculty conditional on $s$, using a Fan (1992) locally weighted regression smoother. Figure 3 plots three estimates of $E\left(\frac{R}{F} \mid s\right)$ : for the 102 universities taken together and for the 68 and 34 public and private universities, separately.

$E\left(\frac{R}{F} \mid s\right)$ is clearly increasing in $s$ and somewhat non-linear: although income is not very responsive to economic incentives at the low range of the royalty shares this is strikingly reversed at shares above 35-40 percent. From Table 2 we know that at least half the universities have expected royalty shares above 40 percent. Also notice the differential response to incentives between private and public universities. These results suggest that university ownership type is an important determinant of how responsive license income is to royalty incentives. To verify these preliminary results and to get some quantitative assessment of the estimated relationships and their precision, we proceed to a regression analysis of the data.

\section{Regression Analysis}

Table 5 presents estimates for equation (5). There are 102 universities in the sample but, because of zero license revenues and other missing data, the regressions in columns (1) and (2) are based on 98 and 97 universities, respectively. ${ }^{22}$ We begin by controlling for faculty size,

after one iteration the average difference in the computed royalty shares for the nonlinear schedules was only 1.3 percentage points, or about 2.8 percent of the mean royalty share. Moreover, using the royalty shares computed after one iteration gave estimated coefficients very close to those obtained using the expected royalty shares based on the unconditional distribution of $v$. The parameter estimates we report are based on the unconditional distribution.

\footnotetext{
${ }^{22}$ There are 749 observations with non-missing license income data. 18 observations have zero license income, reducing the sample to 731 . Using zeros for the observations with zero license revenues does not change the results (if anything, it makes the royalty effect stronger and more significant). Another 14 observations have missing data on other regressors (TLO size, TLO age, R\&D funding) further reducing the sample to 717 observations. See the Appendix for details.
} 
citations per faculty and year dummies. As implied by equation (3), and expected from the non-parametric analysis, the royalty share coefficient is indeed positive but it is also moderately significant $(\mathrm{p}$-value $=0.091)$. The income elasticity of faculty size is above one, but the null hypothesis that it is unity cannot be rejected at the 0.10 significance level. Also, as implied by equation (3), higher quality universities have significantly higher license income.

The sign and magnitude of the estimates is preserved when we add the other controls in equation (5). In column (2), which we treat as the baseline specification, we add the determinants of $\theta-T L O$ size and age - and the other variables in $\omega:$ R\&D funding and the shares of total faculty in each of the main science fields. ${ }^{23}$ The important point to notice is that the estimated incentive effect of royalty shares remains essentially the same as in column (1), but it is more precisely estimated ( $\mathrm{p}$-value=0.049). The regression results point to strong and significant effects of incentives on license revenues. Increasing the inventor's royalty share by 10 percentage points results in a 19 percent increases in revenues. This sizeable effect is one of the main empirical findings of this paper. It confirms the basic economic intuition that monetary incentives do matter for university inventive activity. In view of all the other determinants of license income for which we control, it is striking that we can still pin down an empirical relationship between license income and royalty shares.

The effect of faculty size in column (2) is sharply reduced when adding size-related variables such as $R \& D$ and TLO size (the size coefficient estimate is $0.63=1.35-0.24-0.48$ ). Nevertheless, the null that the size elasticity is unity cannot be rejected at a 0.10 significance level.

Because TLO size and age (i.e., experience) presumably make the TLO more effective in realizing the full potential value of the inventions, we expect positive coefficients for these two variables. We find that license revenue is positively related both to the size and age of the TLO. Increasing the size of the TLO by 10 percent (the average TLO size is 3.1 full-time professionals) would raise license income by 2.4 percent but this effect is not quite significant. We also find returns to experience in TLO activity. An additional year of experience translates into a 2.4 percent increase in license income.

\footnotetext{
${ }^{23}$ For ease of interpretation, TLO size and R\&D funding are entered in the regression on a per faculty basis.
} 
The R\&D variable includes funding from industry, government and non-profit sources. $R \& D$ funding is associated with higher license revenue with an elasticity of 0.48 . Diminishing returns to $R \& D$ set in because we are increasing $R \& D$ funding, holding faculty fixed. If we increase both R\&D and faculty size proportionally, we get close to constant returns to scale - a 10 percent increase in both variables yields a 11.1 (s.e. 0.19) percent increase in license revenue $(1.11=1.35-0.24)$. Finally, as controls for differences in research orientation, we use the fraction of the faculty in each of six technology fields (physical sciences is the reference group). We do find significant technology field differences $(\mathrm{p}$-value $=0.41)$, once we have controlled for R\&D and other characteristics.

\subsection{Public vs Private Universities}

A number of previous studies have examined the relative performance of public and private universities, which is of considerable policy interest. This earlier research has shown that private universities have higher levels of "productivity", measured in terms of scientific publications (Adams and Griliches, 1998) and various outcomes of technology transfer activity (Thursby and Kemp, 2002; Siegel, Waldman and Link, 2003). We ask a different question: does license income respond to monetary incentives differently in public and private universities? Figure 3 suggests that it does: public universities have a milder response to royalty shares than private institutions. In columns (3)-(6) of Table 5 we examine this issue in detail by splitting the sample into public and private universities. ${ }^{24}$

We focus on specifications (4) and (6) based on 66 public and 31 public and private universities, respectively. We observe that royalty shares have a positive incentive effect on license revenue both for private and public universities. The estimated $\delta$ is strongly significant in private universities, but not significantly different from zero for public universities. In this paper we use cluster standard errors which allows for arbitrary heteroskedasticity and serial correlation structure. If we are slightly less demanding and use an $\operatorname{AR}(1)$ specification, we find that the coefficient on royalty share for public universities is also typically significant at the 0.05 level, or very close to it. However, the striking finding is that the incentive effect

\footnotetext{
${ }^{24}$ Pooling is rejected: the test of the null hypothesis that the 19 coefficients, including year dummies, in specification (2) are the same for public and private universities has p-value $=0.01$.
} 
is more than three times larger in private institutions than in public universities. The point estimate implies that a ten percentage point increase in royalty share would increase license income by 58 percent in private institutions. These results confirm the non-parametric findings and show, for the first time, that the degree of faculty responsiveness to royalty incentives depends on university ownership. Since we have controlled for a number of relevant university characteristics, the importance of university ownership type is not driven by these differences.

The other striking finding concerns the effectiveness of the TLO. The estimated elasticity of TLO size on license income is much larger in private universities than in public ones. A 10 percent increase in the number of TLO professionals (equivalent to one-third of a full time employee, at the sample mean of the data) raises license income in private universities by almost 8 percent increases but has no significant effect in public universities. We also allowed the returns to experience to vary by adding a quadratic term in age. The estimated coefficient on the quadratic is insignificant for public universities but significantly negative for private institutions (results not shown). For private universities, an additional year of experience increases revenues by 9.4 percent when TLO age is 8 and 6.4 percent at age 16. For public universities, the estimate is only 2.6 percent. This again suggests important differences in the way TLOs operate: in private institutions experience gains are much larger and are realized earlier than in public universities. Because the addition of age squared to the regression leaves the incentive effects and other parameters essentially unchanged we use the more parsimonious linear specification. ${ }^{25}$ Taken together, these findings on TLO size and age suggest that private institutions have more effective, commercially-oriented technology transfer activity. We discuss why this might be so in Section 5.3. ${ }^{26}$

\footnotetext{
${ }^{25}$ The estimates of $\delta$ are 1.62 (s.e. $\left.=1.33\right)$ and $5.18($ s.e. $=2.15)$ in public and private universities, respectively.

${ }^{26}$ It is worth emphasising at this point that public and private universities in the sample do not differ significantly in any of the observable characteristics that we measure, except quality (private universities are higher). There are no significant differences in faculty size $(380$ and $320, \mathrm{p}$-value $=0.35)$, TLO size $(3.1$ and 3.2 , pvalue $=0.89)$ and age (11.9 and 12.5, p-value=0.78), R\&D funding (149 million and 164 million, p-value=0.70), and the technological mix of the faculty (details omitted). The difference in quality between public and private universities is captured by significant differences in our three measures of quality: the number of citations per faculty, the number of publications per faculty and the NRC quality score. For public universities, the mean of these indicators are 11.7, 6.8 and 2.8, respectively. For private universities, the means are 31.9, 8.6 and 3.4, respectively. These differences are statistically significant ( $\mathrm{p}$-values $<0.01$ ).

The same conclusions are reached if we compare different quartiles, or the whole distribution as confirmed by univariate Kolmogorov-Smirnov tests.
} 


\subsection{Potential Endogeneity of Royalty Shares}

There are two potential sources of endogeneity bias in the OLS estimator of $\delta$. The first is simultaneity bias. One might think that universities that perform poorly in terms of generating license income may set higher inventor royalty shares to improve performance. But this would make our estimates of the incentive effect downward biased. An alternative possibility is that when license income is high the university decides to make good to its faculty by increasing their share of the royalties. This would generate an upward bias in the estimated incentive effect. There is no compelling logic to this type of compensation, in particular when license income is driven by just a few inventions whereas a change in the distribution scheme applies to all inventors. In any case, we expect the simultaneity bias to be relatively small mainly for two reasons: 1) most royalty distribution schemes for universities in our sample were set before the start of the sample period (1991) and, in many cases, they were never changed since the foundation of the TLO and, 2) our finding that royalty shares are weakly related to key observable university characteristics (Table 4) limits the scope to which they can be related to other unobservables features.

The second source of bias is nonreporting bias. A researcher has a choice between reporting (disclosing) the invention and sharing the license revenues with the university, or not reporting it and commercializing it outside (e.g., by forming a private start-up company). If this nonreporting error is uncorrelated with the royalty share, there is no bias in the estimated incentive effect. But suppose the rate of misreporting decreases as the royalty share increases, a reasonable assumption. Then when $s$ increases, part of the observed rise in license revenue would reflect inventors now reporting previously unreported inventions, and the estimator of $\delta$ would be upward biased, i.e., it would overstate the incentive effect of royalty sharing on license income. ${ }^{27}$

Interestingly, this type of bias could potentially explain part of the public-private difference in $\delta$ if misreporting is a more serious problem at private universities. However, we are not aware of any systematic evidence on this issue nor have any good reasons to believe this is actually the case. If anything, our finding that TLOs at public universities are less successful

\footnotetext{
${ }^{27}$ The bias is magnified if the non-reported inventions are more likely to be high valued.
} 
in generating and capturing innovation rents than their counterparts at private universities suggests that misreporting may be more pervasive at public universities.

With the available data we cannot identify the magnitude of this misreporting effect but, because university faculty have a contractual obligation to report invention disclosures to the TLO, it is unlikely that this bias is large enough to undo the estimated positive effect of direct monetary incentives on license income. Of course, from the financial perspective of the university, both the incentive effect and the reporting effect of royalty shares are relevant, since they jointly determine how much license income the university actually earns.

In sum, the two likely sources of bias in our estimator of $\delta$ work in opposite directions and, although they do not have to cancel each other, we have good reasons to believe that they cannot undo the strong positive estimates of the incentive effects. ${ }^{28}$

\subsection{Public vs Private Response: the Gatekeeper Effect}

What accounts for the differential response to royalty incentives in private and public universities? One possible, and simple, explanation for the private-public differential response is that royalty incentives depend to a large extent on the TLO's capability in commercialising faculty inventions. Recall that control rights over inventions always reside with the university so that the TLO effectively has exclusive rights (unless expressly waived) to commercialize the inventions. Because the TLO is the "gatekeeper" (monopsonist over the inventions, as it were), its effectiveness at finding licensees, negotiating agreements and other aspects of commercialising inventions, directly affects the monetary returns to the faculty scientist. Raising the royalty share should have a smaller effect on incentives if faculty scientists anticipate that the TLO will be ineffective at commercialising their inventions.

In this section we explore the issue further. In the model, the scientist's effort can be increased by raising the royalty rate, $s$, or by increasing the effectiveness of the TLO at commercialising the inventions they produce, $\theta$. In fact, under fairly general conditions, the

\footnotetext{
${ }^{28}$ We performed a Hausman test for endogeneity of $s$ by comparing the GLS estimator to the fixed-effect (FE) estimator of $\delta$. The GLS estimator is very similar to the one reported in Table 5 . The FE estimator is feasible because in 11 universities we recorded a change in $s$ over time but, of course, this is precisely what limits our use of the FE estimator. In any case, the GLS and FE are similar to each other, particularly in the private universities, and their difference is not statistically different from zero. The t-value for the difference between $\mathrm{FE}$ and GLS is -0.87 in public universities and -0.29 in private universities.
} 
monetary incentives depend on the interaction between these two parameters. ${ }^{29}$ In the extreme case where $\theta=0$, the share apportioned to faculty will not matter at all. This gatekeeper effect does not appear in the empirical specification - equation (5) - because we log-linearized the revenue function.

This explanation for the private-public difference in responsiveness to royalty incentives is consistent with the finding in Table 5 that the elasticity of license revenues with respect to TLO size is much larger at private universities. But this proxy for $\theta$ is crude. The challenge is to identify characteristics in TLO's that are systematically different in public and private universities and which would help explain why the latter are more effective in generating license income. For this we developed a new survey questionnaire and sent it to directors of TLO's in both public and private universities. ${ }^{30}$ We received 101 responses, of which only 57 were in the regression sample. Table 6 summarizes key results of this survey. First, we find that faculty are well aware of monetary incentives associated with commercialising their inventions, and there is no difference between public and private universities in this regard (row 1). Second, we asked whether the university faculty reward structures (salaries and promotion) gave any significant weight to any measures of technology transfer output. Nearly all report that technology transfer output is not formally rewarded, and again there is no significant difference between university types.

However, we find sharp differences in three key dimensions: use of incentive pay, con-

${ }^{29}$ Formally, differentiating (3)gives

$$
\frac{\partial R}{\partial s}=\theta F v_{0}\left[n(s, \theta) H(s, \theta) \psi^{\prime} \frac{\partial q}{\partial s}+\psi(s, \theta) H(s, \theta) \frac{\partial n}{\partial s}+\psi(s, \theta) n(s, \theta) \frac{\partial H}{\partial s}\right]
$$

where $H(s, \theta) \equiv \int_{\frac{v}{v_{0} \psi(q(s, \theta))}}^{\infty} \varepsilon d G(\varepsilon)$. The "gatekeeper effect" operates if $s$ and $\theta$ are complementary in generating license revenue:

$$
\frac{\partial^{2} R}{\partial \theta \partial s}>0
$$

If the TLO licensed all inventions $(H(s, \theta)=1)$, it is easy to show that this property holds as long as diminishing returns in the production function $n(z)$ and $\psi(q)$ are not too strong (i.e., $n^{\prime \prime}$ and $\psi^{\prime \prime}$ are sufficiently small). The conditions are more complicated when invention quality also affects the probability of being licensed. In this case we also a condition on the distribution of invention values $G(v)$ which requires that the density function $g(v)$ be declining (or not increasing "too much") in $v$. Details are available on request.

${ }^{30}$ We sent the questionnaire to TLO directors in 198 public and private universities. These cover nearly all universities in the U.S. and Canada that are members of the AUTM, and they include both those used in the regression analysis as well as others. After several email and telephone follow-ups, we received a total of 101 responses, of which 57 were in the regression sample. The results of this survey will be analysed more fully in another paper. 
straints, and objectives. First, fewer than half of the TLOs in public universities use any form of performance-based pay (either merit pay or bonuses) in the TLO itself, as compared to 79 percent in private universities (row 3 in Table 6). This difference is strongly significant. The second dimension is the extent to which state government constrains the effectiveness of TLO activity. ${ }^{31}$ The responses were coded on a Likert scale of 1-4 (1=very important, $2=$ moderately important, $3=$ relatively unimportant and $4=$ unimportant). Here we group the responses into two categories - important ( 1 or 2 ) and unimportant ( 3 or 4$)$. The percentage reporting that such constraints were important is very different for public and private universities, for each of the six types of constraints examined. In every case, we find that public universities report that they are more constrained, and the differences are strongly significant (rows 4.1-4.6).

The third dimension examined is the importance of various objectives of the TLO, measured on the 1-4 Likert scale (again, we grouped responses into two categories for this test). As rows 5.1-5.3 in Table 6 show, there is no difference in terms of the importance of the number of licenses or license income, as objectives. However, public universities are much more likely to rank "promoting local or regional economic development" as an important objective, as compared to private universities, and the difference is significant.

These survey findings suggest that the TLO effectiveness in generating license income, $\theta$, is likely to be higher in private universities. In principle, this can help explain our finding that license revenue is more responsive to royalty incentives in private universities. Ideally, we would want to integrate the survey data into the regression analysis, but for this we would need more survey responses from universities included in the regression sample.

\subsection{Is There a Laffer Curve Effect?}

The parameter estimates from Table 5 imply that raising the inventor's royalty share would increase total license income. The point estimate of the semi-elasticity of license revenue with respect to royalty share, $\delta$, implies that raising the inventor royalty share by ten percentage points, say from the sample mean of about 45 to 55 percent, would increase license income by

\footnotetext{
${ }^{31}$ The survey question is: "Does the state government impose any significant constraints that the limit the effectiveness of [your] TLO activity...either explicit forms - such as statutes, regulations, covenants of the university charter - or implicit forms such as pressure from political representatives or agencies." Six specific types of constraints were listed.
} 
16 and 58 percent in public and private institutions, respectively.

Raising the royalty share may even increase license income accruing directly to the university, $(1-s) R$. The semi-elasticity for university's income is $\frac{d \log (1-s) R}{d s}=\delta-\frac{1}{1-s}$. When $\delta>1$ there can be a Laffer effect for universities with sufficiently low royalty rates: i.e., raising the inventor's royalty share would increase the university's license income when $s<s^{*} \equiv 1-\delta^{-1}$. We find such a Laffer effect for all private universities in the sample $\left(s^{*}=0.83\right)$, but only for about a quarter of the public universities, those having $s<s^{*}=0.38$. The incentive effect in these universities is large enough that raising the inventor's royalty share actually increases license income both for the inventor and the university.

Of course, even without a Laffer effect, it may be desirable for a university to raise the royalty share if it attaches weight to the license income for its faculty inventors (e.g., the university could reduce salaries in return for higher royalty shares). To illustrate, suppose the university's objective function $W$ is a linear function of license income plus other variables $y: W=(1-s) R(s)+\lambda s R(s)+y$, where $\lambda<1$ is the weight the university attaches to the faculty's license income. Then $\frac{\partial W}{\partial s}>0$ if $\lambda>1-\frac{\delta}{1+s \delta}$. Using $\delta=1.62$ and the mean of $s=.46$ for public universities, we conclude that raising the royalty share would increase university welfare if $\lambda>0.07$. A rigorous analysis of this issue would require a model of university objectives, policy instruments and the academic labour market, which is beyond the scope of this paper.

\subsection{Incentive Effects: Effort or Sorting?}

Despite our controls for university quality, there is likely to be unobserved heterogeneity in research productivity (or commercial orientation) of faculty. Universities might attempt to attract more productive faculty by offering higher royalty shares, even if compensated by salary reductions to keep the total compensation across faculty constant. If more productive researchers have higher effort elasticities, they will be more responsive to incentives at the margin. If sorting occurs, universities with higher royalty shares have more productive faculty who are more responsive to monetary incentives, which is consistent with the results reported in Tables $5 .{ }^{32}$

\footnotetext{
${ }^{32}$ The responsiveness of license income to $s$ depends on the magnitudes of $\frac{\partial r}{\partial z}$ and $\frac{\partial r}{\partial q}$. For the sorting story to work we need that $\frac{\partial r}{\partial z}$ and $\frac{\partial r}{\partial q}$ be higher for more productive faculty, at the same $(z, q)$. If more productive
} 
As we indicated in Section 3, monetary incentives are likely to work through their impact on the effort levels of individual researchers and through the sorting of scientists across universities. Assessing the relative importance of the effort and sorting channels is important because they have very different policy implications. However, without productivity data for individual inventors, it is difficult to distinguish effort from sorting effects. ${ }^{33}$ Here we develop an indirect test for the presence of a sorting channel based on aggregate data.

The intuition for the test is as follows. Let $s_{i}$ denote the royalty share of university $i$ and $\bar{s}_{i c}$ be the mean share for the set of universities competing with university $i$. Under sorting, the type of faculty a university attracts should depend on how high its royalty share is relative to the set of competing universities. This carries two implications. First, the presence of sorting implies that the effect of $\bar{s}_{i c}$ on the license revenues of university $i$ should be negative. Second, pure sorting, i.e., when effort $(z, q)$ is not affected by $s$, implies that licensing revenue should be homogeneous of degree zero in $s_{i}$ and $\bar{s}_{i c}$. If university $i$ and its competitors were all to increase their inventor's royalty shares by the same amount then the allocation of scientists across universities will not change and, because $s$ does not affect research efforts by hypothesis, license revenues should not change.

To test these predictions, we expand the license income regression to include $\bar{s}_{i c}$ :

$$
\log R_{i}=\delta_{1} s_{i}+\delta_{2} \bar{s}_{i c}+x \beta+\omega \gamma+u
$$

Under pure sorting, we expect that $\delta_{2}<0$ and $\delta_{1}+\delta_{2}=0$. Under a pure effort model, we should find $\delta_{2}=0$. In both cases, we should have $\delta_{1}>0$. When there are both sorting and effort effects, raising the royalty shares for all universities in the same reference group should lead to an increase in innovation and licensing due to the increased effort incentives. Thus, the mixed sorting-effort hypothesis implies $\delta_{1}>0, \delta_{2}<0$ and $\delta_{1}+\delta_{2}>0$.

We assume that a scientist chooses from among "competing" universities. We rank the universities according to a relevant index and define the set of competing universities as those

faculty were not more responsive to changes in revenues, then the sorting mechanism will just affect the revenue level (the constant of the regression) but the not the slope of the $r-s$ relationship.

\footnotetext{
${ }^{33}$ For a recent study of the effects of performance-based pay on effort and sorting, see Lazear (2000). He analyzed the effect on workers' productivity in a large auto glass company as it switched from hour to piece-rate pay, and found that individual productivity increased substantially and the firm attracted a more able workforce.
} 
close to university $i$ in this ranking. Closeness is determined by a window of size $2 k$ around the ranking of university $i$. This means that we averaged the royalty shares of the universities ranked up to (and including) $k$ positions lower and higher than university $i, 2 k$ universities altogether. In defining the competing universities, we pool public and private universities, although we estimate the model separately for the two types. We experimented with two different window sizes, $k=2,3$.

For this test we use two alternative criteria to define competing universities: the level of total R\&D funding per faculty and the number of citations per faculty. In the new survey of TLO directors we conducted, we asked whether "staying in line with competing universities" was an important consideration in setting royalty sharing rates and, if so, how they would define that group. R\&D funding and academic quality were the two most frequently listed criteria.

Table 7 summarises the estimates of $\delta_{1}$ and $\delta_{2}$ (other parameters are omitted for brevity) Using R\&D funding per faculty (Panel A), we find clear evidence that sorting operates for private universities. For each window size, the coefficient on the royalty share for the competitor's group, $\delta_{2}$, is negative and statistically significant. Because of the large standard errors of $\widehat{\delta}_{2}$ the point estimate of $\delta_{1}+\delta_{2}$ is actually quite close to zero, and we cannot formally reject the zero homogeneity hypothesis, $\delta_{1}+\delta_{2}=0$. Given the associated standard error, we also would not reject the hypothesis that $\delta_{1}+\delta_{2}$ is positive. For public universities, we find no evidence of any sorting effect, but nor do we find any direct incentive effect either. When we use citations per faculty to identify competing universities (Panel B), the point estimates again indicate sorting behaviour for private universities, but the parameter estimates are not statistically significant.

In short, the evidence indicates that the effect of royalty shares on licensing revenues in private universities works both through effort and sorting channels, but we cannot pin down their relative importance of these channels with the available university-level data.

\subsection{Incentive Effects on Invention Quantity and Quality}

License revenue per faculty depends both on the number of inventions and their value. It is natural to ask wether one can distinguish between the quantity $(n)$ and the quality $(v)$ components of the royalty share effect on license revenue. It turns out that the available 
aggregate data allow us to address this question.

Let $L$ be the the number of licenses obtained from $n F$ invention disclosures. That is, $L=n(z(s, \theta)) F \int_{\frac{v}{v_{0} \psi(q(z, \theta))}}^{\infty} \varepsilon d G(\varepsilon)$. Substituting into the revenues equation (3) gives

$$
R=\theta v_{0} \psi(q(s, \theta)) L
$$

If the royalty share $s$ has an effect on the quality of inventions, then this equation says that $s$ should have an effect on license revenues even after we control for the number of licenses. If we do not observe this, then we can conclude that the incentive effects of royalty sharing work only through the quantity of inventions, but not their quality. The elasticity of revenues with respect to licenses should be one.

Table 8 presents results of estimating equation (7) using a log approximation and the cumulative number of active licenses. Data on the latter are available only since 1995, so for purposes of comparison, the baseline regressions are shown in columns (1) and (5) for the same period 1995-99. Notice that these estimates are very similar to those in Table 5 using the full sample. We find that controlling for $L$ reduces the estimated effect of royalty shares on revenues but it does not eliminate it completely. ${ }^{34}$ This is particularly true in private universities, but less so in public ones where the incentive effect was not significantly different from zero even when $L$ was not controlled for. The estimates imply that increasing the royalty share at private universities by 10 percentage points will generate 38 percent more license revenue, given the same number of licenses. Because the total effect of such a change in royalty shares on license revenues is much higher - about 58 percent (Table 5) - it follows that the number of inventions is also affected by the royalty share.

Actually, we can gauge the effect of $s$ on the quantity of inventions directly by regressing the available proxies for the number of inventions on $s$ and the other controls. We use two imperfect measures of inventions: the number of licenses executed and the number of invention disclosures, both of them flow measures. These quantity regressions are presented in columns

\footnotetext{
${ }^{34}$ As expected, the coefficient on $\log L$ is not significantly different from one. Also notice that faculty size does not appear in equation (7) once $L$ is included. Adding $F$ to the regressions in columns (2) and (6) does not affect the results at all. For example, adding $\log F$ to column (2) reduces the license coefficient from 0.77 to $0.64(0.19)$ and increases the coefficient on royalty share from 1.20 to 1.51 (1.55). Adding $\log F$ to column (6) reduces the license coefficient from 0.77 to $0.76(0.31)$ and increases the coefficient on royalty share from 3.83 to $3.94(1.89)$.
} 
(3)-(4) and (7)-(8). ${ }^{35}$ There is no real evidence that royalty incentives have any effect on the number of inventions in public universities. The other controls have the expected signs. Notice, in particular, the significant positive effect of the TLO. In private universities, we find a positive and significant effect of $s$ on the number of licenses executed but no effect on the number of disclosures. Increasing the royalty share at private universities by 10 percentage points will generate 26 percent more licenses. Added to the 38 percent increase in the mean value of licensed inventions (column (6)), this gives a predicted effect on license income of 64 percent, which is very close to the 58 percent effect found in Table 5 , even though the regressions are based on different cuts of the data. The main implication of this analysis is that the quality channel is more important than the quantity channel in private universities. In public universities, however, $s$ has a an overall very weak effect because neither quantity nor quality seems to be affected by royalty incentives.

The use of quantity measures in these regression may introduce measurement error because of the possibility that faculty do not report all their inventions to the TLO. We now show that this is likely to bias the effect of royalty shares upward in the quantity regression, and downward in the revenue regression. Let $N^{*}$ be the true number of disclosures at the university and let $N$ be the observed number ( $n F$ in the model). Assume

$$
N=N^{*}(1-\rho) \quad 0 \leq \rho \leq 1
$$

where $\rho$ is the rate of misreporting. When $\rho=0$ faculty reports all inventions to the TLO. Similarly, the true and observed number of licenses are

$$
\begin{aligned}
L^{*} & =N^{*} H(s) \\
L & =N H(s)=L^{*}(1-\rho)
\end{aligned}
$$

where $H(s) \equiv \int_{\frac{v}{v_{0} \psi(q(z, \theta))}}^{\infty} \varepsilon d G(\varepsilon)$.

In the license income regression, when $\log L$ is used instead of $\log L^{*}$ as a regressor in columns $(2)$ and $(6)$, it adds $-\log (1-\rho)$ to the error in the regression. If $\rho$ and $s$ are not correlated then there is no bias. However, if $\operatorname{Cov}(\rho, s)<0$, i.e., misreporting decreases as the inventor's royalty share increases, then $s$ and $-\log (1-\rho)$ are negatively correlated and we get a

\footnotetext{
${ }^{35}$ Disclosure data are available for all years, but the number of licenses executed are available only for 1991-96.
} 
downward bias in the estimated coefficient of $s$ in the regressions in columns (2) and (6). The coefficient of $\log L$ would also be biased downward.

In the quantity regressions, using $\log N$ or $\log L$ as dependent variable instead of $\log N^{*}$ or $\log L^{*}$ adds $\log (1-\rho)$ to the error in the regression. If $\operatorname{Cov}(\rho, s)<0$, then $s$ and $\log (1-\rho)$ are positively correlated and there is an upward bias in the estimated coefficient of $s$ in the quantity equation. That is, part of the observed rise in the number of inventions, associated with an increase in $s$, is due to the reporting of previously unreported invention rather than to new inventions. Thus the point estimate of the incentive effect on the quantity of inventions in private universities may overstate its true effect.

The direction of the possible biases in both the income and the number of licenses regressions reinforce our conclusion that the incentive effect of royalty sharing works predominantly through the quality channel.

\section{Robustness Checks}

In this section we discuss a variety of extensions to the baseline specification in Table 5, estimated separately for public and private universities. We focus on the robustness of the estimated incentive effect of inventor royalty shares, but there is also independent interest in some of the specifications we examine.

First, we check robustness of the parameter estimates to "outliers." As pointed out in Section 2, the distribution of license income is highly skewed across universities. This raises a concern that our empirical results may be driven by a few outliers in the sample in terms of the dependent variable. We address this issue in two different ways: (1) we re-estimate the model dropping the top license income earners, and (2) we estimate the model using median regression (this procedure minimizes the sum of absolute deviations and thus gives less weight to outliers). Table 9 presents the results. For the first experiment, we drop three universities from the sample: the University of California System in the public university sample, and Stanford and Columbia Universities in the private sample. These were the top earners over the sample period and their license income was an order of magnitude higher than other universities. For private universities, the estimated coefficients on the royalty share are slightly lower than the least squares estimates in Table 5, but still very large and significant. Dropping California 
does not affect the estimated $\delta$ in public universities, but using the median regression cuts the estimate in half. The elasticity of TLO size in public universities is also increased considerably when median regression is used. Overall, the finding of a strong incentive effect in private universities and of a much weaker effect in public universities is not affected by the presence or absence of the top license earners. ${ }^{36}$

Second, we introduced dummy variables to capture the Carnegie Foundation research classification of universities (doctoral/research universities, master's colleges and universities, etc.). The coefficients are not significantly different from zero and do not affect the estimated incentive effects or other coefficients (results not reported). The estimated $\delta$ is 1.53 (1.36) and 5.78 (2.15) in public and private universities, respectively. The same conclusions hold when we introduce a dummy for the presence of a medical school at the university. ${ }^{37}$

Third, we re-estimate the model using alternative measures of quality: the number of publications per faculty, the NRC scholarly quality score and the average faculty salary at the university (Table 10). All the alternative measures affect revenues in a positive way at private universities. Also, the point estimates of the incentive effect, although marginally lower than in the baseline specification, where citations per faculty are used (Table 5), remain quite high. None of the quality measures affects license revenues in public universities either individually or jointly. Nor is the estimated effect of royalty shares affected by the use of a particular quality proxy. The remaining parameters estimates are also robust to the choice of quality proxy, both for public and private universities.

Fourth, we allow for the possibility that the incentive effect of royalty shares varies with two characteristics of the university: quality and the percentage of faculty which is tenured. Turning first to quality, it is commonly argued that faculty at more prestigious institutions are likely to be motivated mainly by scientific recognition and status rather than by monetary rewards. In the model this takes the form of a lower marginal utility of license revenue in

\footnotetext{
${ }^{36}$ The standard errors of the median regression are not robust standard errors. We also estimated quantile regressions for the first and third quartiles. In public universities, the estimated $\delta^{\prime} s$ are $0.15(.11)$ and 1.20 (0.75), respectively. In private universities, the estimates are 3.9 (1.4) and 5.3 (1.9), respectively.

${ }^{37}$ The medical dummy is not significant in public universities and marginally significant in private ones with a positive coefficient equal to $1.4(0.78)$. The estimated $\delta$ is $1.62(1.32)$ and $6.69(2.11)$ in public and private universities, respectively. The same conclusions holds if we use the medical school dummy instead of the technology fields shares.
} 
higher quality universities. To test this, we include interactions terms between the inventor royalty share and dummy variables for the lowest and highest quartile of the citations per faculty distribution (Columns 1 and 3, Table 11). In support of the popular view, we find that the incentive effects of royalty shares declines with university quality. In public universities the estimated coefficient declines from 3.4 (s.e.=1.8) in the first quartile of the quality distribution to 1.6 (s.e. $=1.02)$ in the fourth quartile. In private universities, we find the same pattern: $\widehat{\delta}$ is 6.6 (s.e. $=1.63)$ in the first quartile and declines to $4.8($ s.e. $=2.25)$ in the fourth quartile.

Turning to faculty tenure, if doing research that produces commercially usable inventions comes at the cost of doing less (quality-adjusted) academic publications, then one would expect untenured faculty members to be less responsive to royalty shares than tenured members. To test this, we include interactions terms between the inventor royalty share and dummy variables for the lowest and highest quartile of the tenure distribution (the percentage of tenured faculty at each university). As columns 2 and 4 (Table 11) show, the hypothesis is confirmed for public universities. The incentive effect of royalty shares is significant and positive in the top quartile of the tenure distribution, but not in the lower three quartiles. This is particularly interesting, since the baseline estimate of the incentive effect for public universities was not significantly different from zero (Table 5). For private universities, there is no support for the hypothesis, but the estimated incentive effects are again much larger than for public universities and statistically significant.

In Table 12 we allow industry and publicly-funded $R \& D$ to have different effects on licensing income. Publicly-funded R\&D has a positive effect on license revenue, but it is significant only in public universities. The point estimates of the elasticities imply that raising public R\&D by 10 percent would increase license revenue by about 4 percent. ${ }^{38}$ By contrast, we find that industry-financed $\mathrm{R} \& \mathrm{D}$ has no significant effect on license income. This is what one would expect if the bulk of such funding is contract $R \& D$ with free licensing provisions (i.e., ex ante R\&D funds are given in place of ex post licensing income). One could even argue that industry-financed $\mathrm{R} \& \mathrm{D}$ may reduce the average license income received by the university

\footnotetext{
${ }^{38}$ Payne and Siow (2003) analyze the effect of federal funding on university research. Using a sample of 68 research universities, they conclude that increasing federal research funding results in more, but not necessarily higher quality, research output.
} 
because the firms are likely to get more favorable licensing arrangements. Importantly, the estimated coefficients on the royalty shares, and on the other regressors, are nearly identical to the baseline case.

Finally, we added a variable to control for differences in the potential demand for licenses by private firms. If demand for licensing is localized, because of information or other factors, universities located in more dense high-tech areas should license more inventions from a given pool of invention disclosures and obtain more revenue. Moreover, faculty response to incentives may depend on local demand factors. A more developed local high-tech market may increase faculty awareness of the potential rewards to university inventions. On the other hand, it may also increase the demand for faculty consultants, advisors, and other type of scientific endeavours that compete with university research time making university monetary incentives less relevant.

To address this issue, we use the 1995 Milken index of high-tech activity for the area where the university is located (Friedman and Silberman, 2003). ${ }^{39}$ The index is a continuous variables ranging from zero to a maximum of 23.7 (for Stanford University) but we discretized it by grouping universities into three groups: universities in the first quartile of the Milken index distribution, universities in the second and third quartiles and universities in the fourth quartile. Royalty shares do not vary much with the Milken index of high-tech activity: the average $s$ at universities in the three groups is 42,47 and 43 percent, respectively. This suggests that royalty shares are not set in response to the value of outside options available locally to university scientists. Table 13 shows the results of the baseline models with dummies for the first and fourth quartile and their interaction with $s$.

The local demand argument implies that the coefficients of the dummies representing each of the three groups should be increasing as we move from the first to the fourth quartile. We find a strong local, high-tech demand effect for private universities but not public ones. License revenues in private universities located in the most dense high-tech areas are over 300 percent higher than comparable universities in less high-tech surroundings (we reject that the coefficients on the dummies are jointly zero, p-value $<0.01$ ). But license revenues in

\footnotetext{
${ }^{39}$ Nine observations are dropped because the index is not available.
} 
public universities do not vary with the index of local demand (the coefficients on the two dummies are not different from zero, $\mathrm{p}$-value $=0.86$ ). This finding again suggests that private universities are more effective than public ones to exploit the potential of being located in hightech areas. But the fact that local demand conditions matter at all indicates the importance of structuring technology transfer institutions so that they can more effectively exploit demand for inventions in non-local areas. For this purpose, specialization of TLO's by university (the current arrangement) may be inferior to alternatives such as having TLO's that specialize by technology area and serve multiple universities.

The responsiveness to monetary incentives again differs by ownership type. In public universities, the royalty effect does not vary much with the index of local demand (we cannot reject the hypothesis that the interaction terms are zero, p-value $=0.88)$. In private universities, however, the responsiveness to the inventor's royalty share exhibits a clear pattern: $\widehat{\delta}$ decreases sharply from about 12 at universities located in low high-tech areas to about 4 at universities in the fourth quartile (the p-value for the test that the interaction coefficients are zero is 0.08). Though speculative, this finding is consistent with the argument that a concentration of high-tech firms may lure faculty away into consultancy jobs and lower their responsiveness to university incentives.

\section{Concluding Remarks}

In this paper we exploit cross-university variation in the share of licensing royalties received by academic scientists in order to estimate the effect of monetary incentives on inventive output, as measured by the license income generated by the inventions.

We report two main results. First, we show that academic research and inventive activity in universities respond to variations in inventors' royalty shares. Controlling for a variety of other determinants, including university size, quality, R\&D funding and local demand conditions, we find that universities with higher royalty shares generate higher levels of license income. This finding is important because it implies that the design of intellectual property rights, and other forms of incentives, in academic institutions can have real effects. We also explore whether the incentive effects of royalty sharing work by inducing greater effort by scientists or through sorting of scientists across universities. We find evidence of sorting effects, 
but we cannot pin down the relative contribution of effort and sorting with the available data. We also show that these incentive effects work primarily by increasing the quality, rather than the quantity, of inventions.

Second, we show that the response to incentives, and the effectiveness of technology licensing offices, are much larger and more significant in private universities than in public ones. In order to rationalise this sharp difference, we argue that there is a "gatekeeper effect": because TLOs in public universities are less effective at commercialising inventions, the incentive effect of higher royalty shares is muted. We provide survey evidence that the use of incentives, the constraints and the objectives of TLOs in public and private universities differ in ways that are consistent with this claim. Finally, in private universities the incentive effect is strong enough to produce a Laffer effect, where raising the inventor's royalty share would increase the license revenue actually retained by the university.

There are three main directions for further research. The first is to combine the data in this paper with information on the objectives, internal incentives and organisational structure of technology licensing offices, in order to understand why private universities perform so much better than public ones in technology transfer. The second avenue is to examine universitylevel data (and other public research organisations) for other OECD countries in which there is variation both in cash flow and control rights. The third, and most ambitious, avenue is to model university behavior and the academic labour market, incorporating pecuniary incentives (salaries and royalties), multi-tasking and career concerns. To do this will require a suitable specification of the objectives and decision-making rules of the university. Such a model could be used as the basis for more detailed studies of incentives and university research using microdata on academic scientists. 


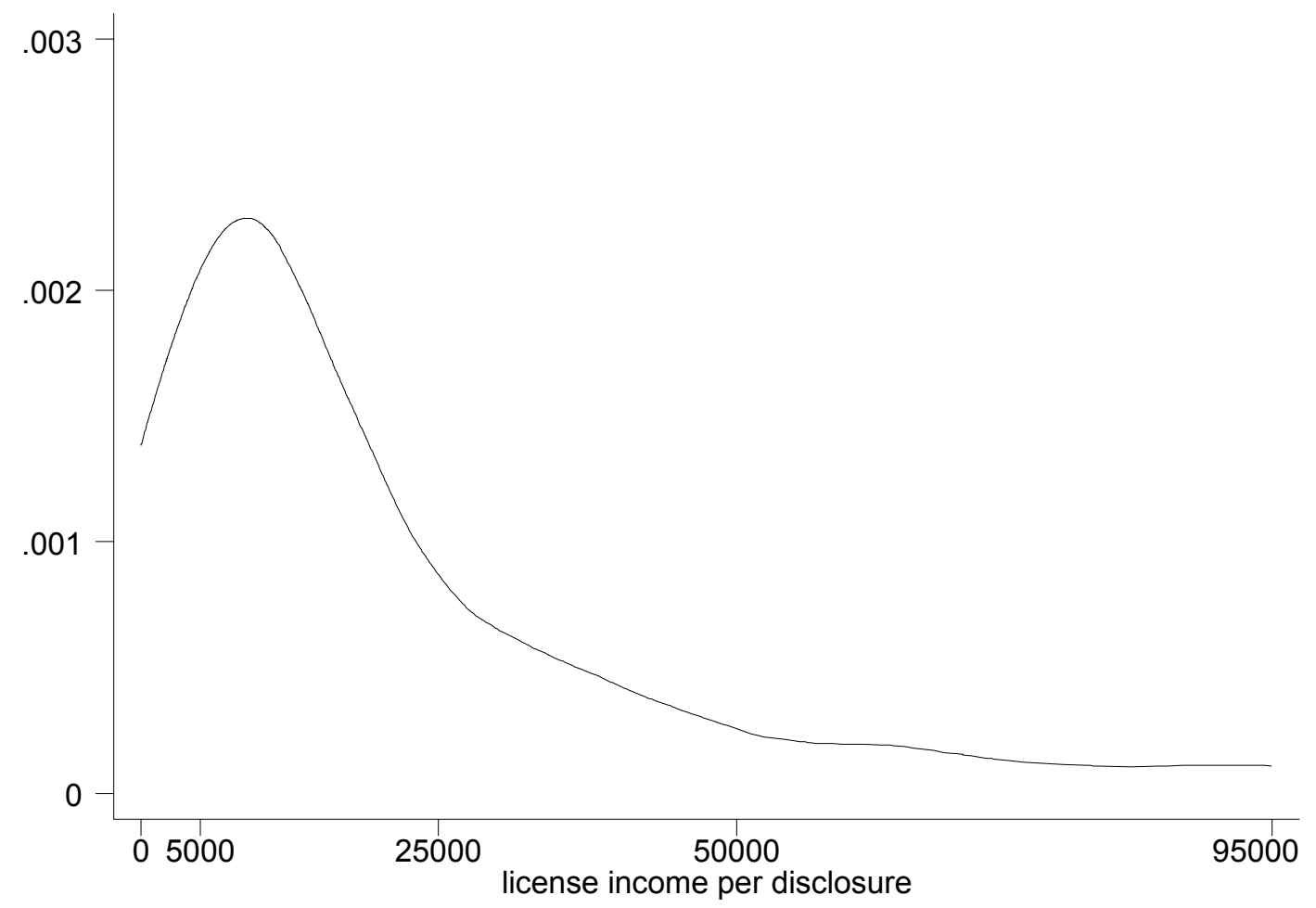

Figure 1. Estimated Density of License Income per Disclosure 


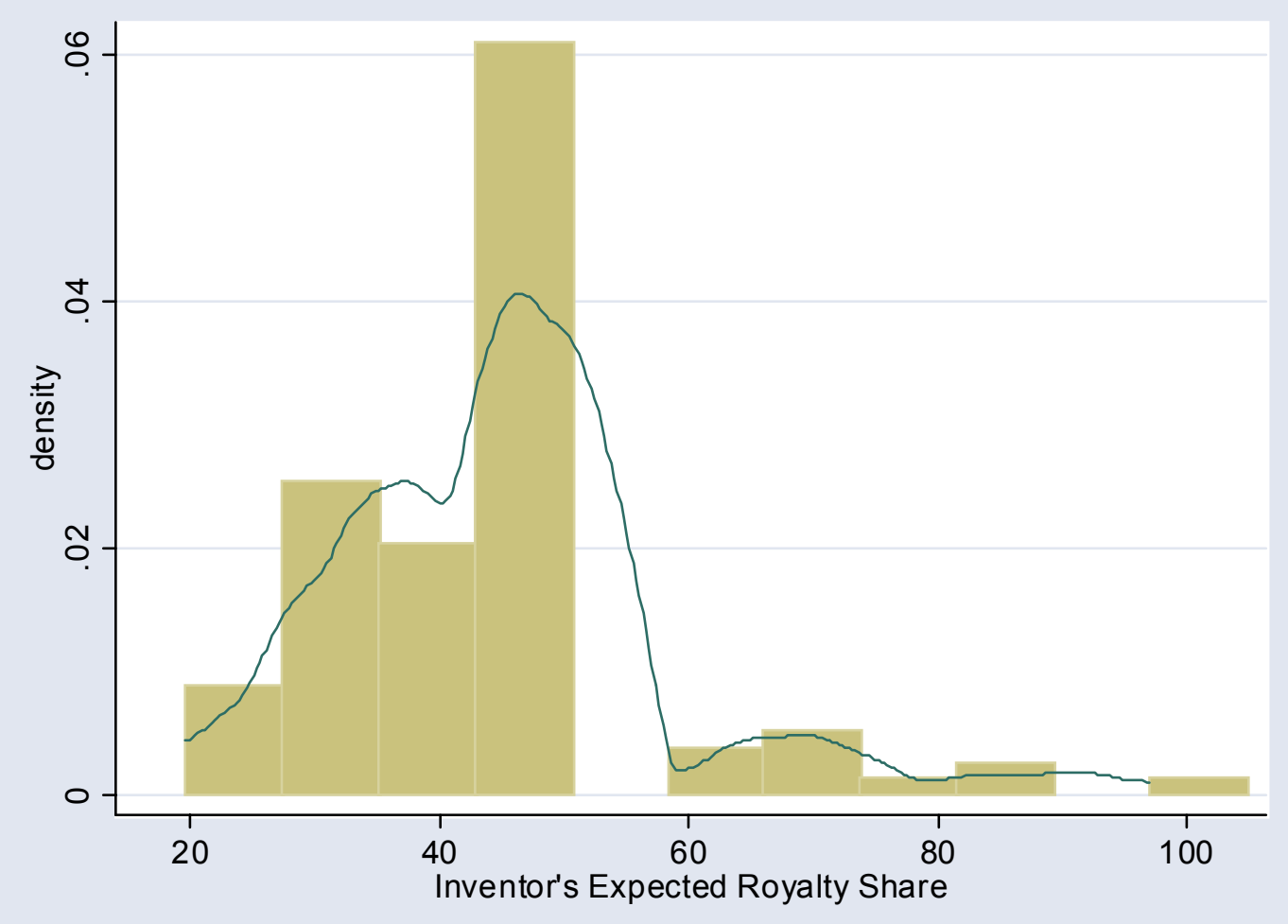

Figure 2: Distribution of Expected Inventor's Royalty Shares 


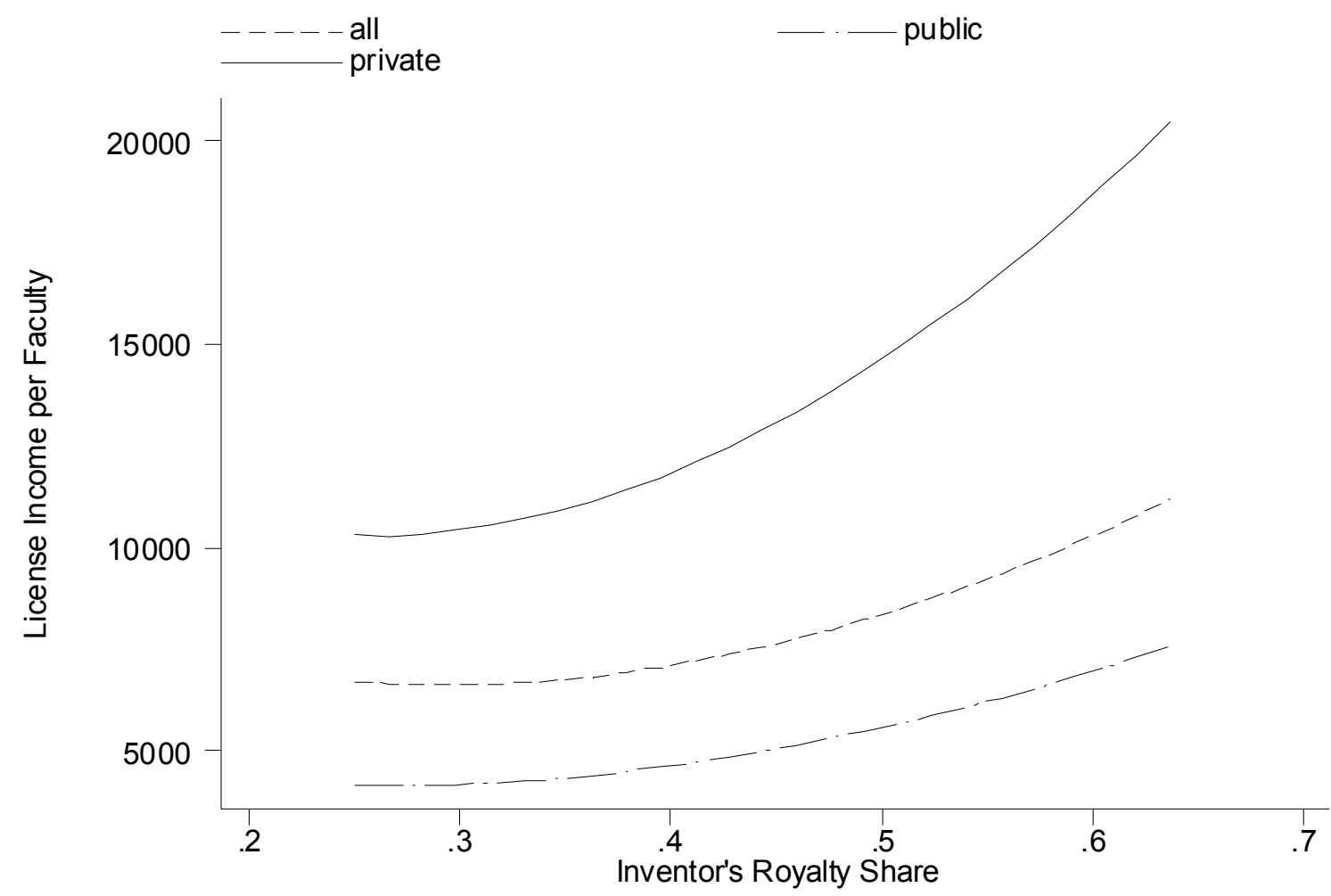

Figure 3: Plots of $E\left(\frac{R}{F} \mid s\right)$ 
Table 1. Descriptive Statistics ${ }^{1}$

\begin{tabular}{|c|c|c|c|c|c|c|}
\hline Variable & $\mathrm{N}$ & Mean & Std. Dev. & $25 \%$ & $50 \%$ & $75 \%$ \\
\hline 1. Licensing income ('000s) ${ }^{2}$ & 102 & $3,351.6$ & $8,103.8$ & 162.3 & 620.1 & 2,942 \\
\hline 2. Licensing income ('000s) per license $e^{2,3}$ & 96 & 48.2 & 162.8 & 9.5 & 17.3 & 39.4 \\
\hline 3. No. of invention disclosures & 102 & 66.9 & 81.0 & 19.5 & 44.7 & 81.1 \\
\hline 4. No. of invention disclosures per faculty & 102 & 0.22 & 0.19 & 0.11 & 0.17 & 0.26 \\
\hline 5. Faculty Size & 102 & 360 & 369 & 136 & 288 & 494 \\
\hline 6. Citations per faculty 4 & 102 & 18.5 & 22.7 & 5.1 & 11.7 & 21.2 \\
\hline 7. Publications per faculty ${ }^{4}$ & 102 & 7.4 & 3.0 & 5.2 & 7.1 & 9.7 \\
\hline 8. Scholarly quality (0-5) & 102 & 3.0 & 0.8 & 2.5 & 3.1 & 3.6 \\
\hline 9. Average size of $T L O^{5}$ & 102 & 3.1 & 5.2 & 1.0 & 2.0 & 3.3 \\
\hline 10. Age of TLO in 1999 (years) & 99 & 16.0 & 12.6 & 8.0 & 13.0 & 17.0 \\
\hline
\end{tabular}

Notes:

${ }^{1}$ Statistics computed on the time-averaged data for each of the $N$ universities.

${ }^{2}$ Income data in nominal dollars.

${ }^{3}$ Licensing income in year $t$ divided by the cumulative number of active licenses through year $t$.

${ }^{4}$ During 1988-92.

${ }^{5}$ Number of full time professionals employed by the TLO. 
Table 2. Distribution of Inventor Royalty Shares (percent) ${ }^{1}$

\begin{tabular}{|c|c|c|c|c|c|c|}
\hline & Mean & $25 \%$ & $50 \%$ & $75 \%$ & Min & $\operatorname{Max}$ \\
\hline Linear Schedules (No. universities $=58$ ) & 41 & 33 & 40 & 50 & 21 & 65 \\
\hline $\begin{array}{l}\text { Nonlinear Schedules: Expected Royalty Share }{ }^{2} \\
(\text { No. universities }=44)\end{array}$ & 51 & 42 & 49 & 49 & 20 & 97 \\
\hline \multicolumn{7}{|l|}{ Income Interval: } \\
\hline $0-10,000$ & 53 & 43 & 50 & 50 & 20 & 100 \\
\hline $10,000-50,000$ & 45 & 40 & 50 & 50 & 20 & 93 \\
\hline $50,000-100,000$ & 42 & 33 & 44 & 50 & 20 & 85 \\
\hline $100,000-300,000$ & 35 & 29 & 33 & 40 & 20 & 85 \\
\hline $300,000-500,000$ & 33 & 25 & 30 & 40 & 20 & 85 \\
\hline 500,000-1 million & 32 & 25 & 30 & 35 & 20 & 85 \\
\hline Over 1 million & 30 & 25 & 30 & 34 & 15 & 85 \\
\hline
\end{tabular}


Table 3. Inventor Royalty Shares (percent) by University Characteristics ${ }^{1}$

\begin{tabular}{lccc}
\hline \hline & & & \\
& Faculty Size & Citations per Faculty & TLO Size per Faculty \\
$1^{\text {st }}$ quartile & 50 & 48 & 44 \\
$2^{\text {nd }}$ quartile & 43 & 43 & 48 \\
$3^{\text {rd }}$ quartile & 44 & 46 & 46 \\
$4^{\text {th }}$ quartile & 43 & 44 & 43 \\
F-test & 1.67 & 0.74 & \\
(p-value) & $(0.18)$ & $(0.53)$ & 0.55 \\
& & & $(0.65)$
\end{tabular}

Notes:

${ }^{1}$ Using time-averaged data for the 102 universities. 
dependent variable: expected royalty share $(s \times 100)$

\begin{tabular}{|c|c|c|c|c|}
\hline Constant & $\begin{array}{l}46.1^{* *} \\
(7.28)\end{array}$ & $\begin{array}{l}54.7^{* *} \\
(13.3)\end{array}$ & $\begin{array}{l}56.1^{* *} \\
(15.2)\end{array}$ & $\begin{array}{l}60.1^{* *} \\
(18.2)\end{array}$ \\
\hline Faculty size & $\begin{array}{c}-0.006 \\
(.009)\end{array}$ & $\begin{array}{c}-0.005 \\
(.009)\end{array}$ & $\begin{array}{c}-0.022^{*} \\
(.012)\end{array}$ & $\begin{array}{c}-0.021 \\
(.014)\end{array}$ \\
\hline Citations/faculty & $\begin{array}{c}-0.15 \\
(.10)\end{array}$ & $\begin{array}{l}-0.15 \\
(0.10)\end{array}$ & $\begin{array}{c}-0.24^{* *} \\
(.10)\end{array}$ & $\begin{array}{c}-0.19 \\
(.13)\end{array}$ \\
\hline Publications/faculty & $\begin{array}{c}0.58 \\
(1.00)\end{array}$ & $\begin{array}{c}0.96 \\
(1.11)\end{array}$ & $\begin{array}{l}-1.16 \\
(1.13)\end{array}$ & $\begin{array}{c}0.87 \\
(1.25)\end{array}$ \\
\hline Quality index & $\begin{array}{l}-0.11 \\
(4.82)\end{array}$ & $\begin{array}{l}-2.79 \\
(4.48)\end{array}$ & $\begin{array}{l}-0.11 \\
(4.65)\end{array}$ & $\begin{array}{c}2.02 \\
(5.30)\end{array}$ \\
\hline Biomedical & - & $\begin{array}{l}-0.03 \\
(11.6)\end{array}$ & $\begin{array}{l}-6.11 \\
(13.7)\end{array}$ & $\begin{array}{l}-2.39 \\
(15.6)\end{array}$ \\
\hline Other Biological & - & $\begin{array}{l}-6.63 \\
(11.5)\end{array}$ & $\begin{array}{l}-9.98 \\
(13.3)\end{array}$ & $\begin{array}{l}-8.15 \\
(14.9)\end{array}$ \\
\hline Computer Science & - & $\begin{array}{c}53.0 \\
(54.0)\end{array}$ & $\begin{array}{c}35.3 \\
(50.8)\end{array}$ & $\begin{array}{c}39.8 \\
(58.4)\end{array}$ \\
\hline Chemical Science & - & $\begin{array}{l}-18.2 \\
(15.7)\end{array}$ & $\begin{array}{l}-22.8 \\
(14.8)\end{array}$ & $\begin{array}{l}-19.4 \\
(15.6)\end{array}$ \\
\hline Engineering & - & $\begin{array}{l}-14.1 \\
(15.8)\end{array}$ & $\begin{array}{l}-13.7 \\
(17.5)\end{array}$ & $\begin{array}{l}-9.50 \\
(21.3)\end{array}$ \\
\hline TLO size & - & - & $\begin{array}{c}1.56 \\
(1.09)\end{array}$ & $\begin{array}{c}1.45 \\
(1.14)\end{array}$ \\
\hline TLO age & - & - & $\begin{array}{c}-0.38^{* *} \\
(0.13)\end{array}$ & $\begin{array}{c}-0.41^{* *} \\
(0.13)\end{array}$ \\
\hline R\&D (millions) & - & - & - & $\begin{array}{l}0.004 \\
(.030)\end{array}$ \\
\hline Private University & - & - & - & $\begin{array}{l}-1.92 \\
(3.15)\end{array}$ \\
\hline Average Salary ('000s) & & & & $\begin{array}{c}-0.25 \\
(.32)\end{array}$ \\
\hline $\begin{array}{l}R^{2} \\
\text { Test for zero coefficients }\end{array}$ & 0.05 & 0.12 & 0.24 & 0.26 \\
\hline $\begin{array}{l}p \text {-value } \\
\text { No. obs. }\end{array}$ & $\begin{array}{c}0.251 \\
102\end{array}$ & $\begin{array}{c}0.314 \\
102\end{array}$ & $\begin{array}{c}0.010 \\
99\end{array}$ & $\begin{array}{c}0.003 \\
97\end{array}$ \\
\hline
\end{tabular}

Notes:

Using time-averaged data for the 102 universities, when available.

In parenthesis, heteroskedasticty-robust standard errors using the $H_{3}$ finite-sample correction (Davidson and MacKinnon, p. 554).

* Significant at the $5 \%$ level

** Significant at the $1 \%$ level 


\begin{tabular}{|c|c|c|c|c|c|c|}
\hline & \multicolumn{2}{|c|}{ All Universities } & \multirow{2}{*}{$\begin{array}{l}\text { Private } \\
\quad(3)\end{array}$} & \multirow{2}{*}{$\begin{array}{c}\text { Universities } \\
(4)\end{array}$} & \multicolumn{2}{|c|}{ Public Universities } \\
\hline & $(1)$ & $(2)$ & & & $(5)$ & $(6)$ \\
\hline \multirow[t]{2}{*}{ Royalty share } & 1.85 & $1.91^{* *}$ & $4.09^{* *}$ & $5.82^{* *}$ & 0.80 & 1.62 \\
\hline & $(1.09)$ & $(.96)$ & $(1.04)$ & $(2.11)$ & $(1.35)$ & $(1.34)$ \\
\hline \multirow[t]{2}{*}{ Log faculty size } & $1.22^{* *}$ & $1.35^{* *}$ & $0.91^{* *}$ & $1.59^{* *}$ & $1.36^{* *}$ & $1.41^{* *}$ \\
\hline & $(.144)$ & $(.142)$ & $(.261)$ & $(.277)$ & $(.140)$ & $(.166)$ \\
\hline \multirow[t]{2}{*}{ Citations/faculty } & $0.023^{* *}$ & $0.015^{* *}$ & $0.025^{* *}$ & $0.018^{* *}$ & 0.018 & 0.007 \\
\hline & $(.005)$ & $(.004)$ & $(.006)$ & $(.005)$ & $(.013)$ & $(.014)$ \\
\hline \multirow[t]{2}{*}{$\log (R \mathscr{E} D /$ faculty $)$} & - & $0.480^{* *}$ & - & 0.36 & - & $0.48^{* *}$ \\
\hline & & $(.225)$ & & $(.329)$ & & $(.203)$ \\
\hline \multirow[t]{2}{*}{$\log (T L O /$ faculty) } & - & 0.243 & - & $0.774^{* *}$ & - & -0.009 \\
\hline & & $(.162)$ & & $(.317)$ & & $(.159)$ \\
\hline \multirow[t]{2}{*}{ Age TLO } & - & $0.024^{* *}$ & - & 0.010 & - & $0.026^{* *}$ \\
\hline & & $(.009)$ & & $(.016)$ & & $(.010)$ \\
\hline \multirow[t]{2}{*}{ Biomedical } & - & 0.82 & - & 0.55 & - & 1.17 \\
\hline & & $(1.14)$ & & $(2.33)$ & & $(1.41)$ \\
\hline \multirow[t]{2}{*}{ Other Biological } & - & 0.06 & - & 1.60 & - & -0.89 \\
\hline & & $(1.09)$ & & $(2.53)$ & & $(1.36)$ \\
\hline \multirow[t]{2}{*}{ Computer Science } & - & 2.88 & - & -4.00 & - & 2.85 \\
\hline & & $(2.85)$ & & $(8.06)$ & & $(2.57)$ \\
\hline \multirow[t]{2}{*}{ Chemical Science } & - & 0.39 & - & 4.10 & - & 0.66 \\
\hline & & $(1.35)$ & & $(6.45)$ & & $(1.54)$ \\
\hline \multirow{2}{*}{ Engineering } & - & 1.53 & - & 3.47 & - & 0.97 \\
\hline & & $(1.28)$ & & $(2.50)$ & & $(1.52)$ \\
\hline$R^{2}$ & 0.50 & 0.60 & 0.50 & 0.69 & 0.52 & 0.61 \\
\hline No. obs. & 731 & 717 & 250 & 246 & 481 & 471 \\
\hline No. Universities & 98 & 97 & 32 & 31 & 66 & 66 \\
\hline
\end{tabular}

Notes:

Standard errors clustered by university in parentheses. Year dummies included in all regressions.

* Significant at the $5 \%$ level, ${ }^{* *}$ Significant at the $1 \%$ level 


$\begin{array}{cll}\text { Public } & \text { Private } & \text { P-value of Equality } \\ \text { Universities } & \text { Universities } & \text { of Means Test }\end{array}$

1. Faculty Awareness of Incentives

$\%$ responding YES

91.7

96.4

0.41

2. University Rewards Technology Transfer $\%$ responding YES

15.4

0.42

3. Incentive-pay

$\%$ using incentive pay ${ }^{2}$

49

79

0.007

4. Government constraints on:

$\%$ reporting important

4.1. Choice of license partners

23

$<.001$

4.2. Setting license contract terms

19

27

$<.001$

4.3.License confidentiality

23

$<.001$

4.4 Use of equity stakes

75

0.024

4.5 University liability/indemnification

49

4.6. Dispute resolution mechanisms

3.5

3.80

5. Objectives

$\%$ reporting important

5.1 Number of licenses

5 2. License income

5.3 Promoting local/regional development

$97 \quad 100$

0.38

$\begin{array}{lll}88 & 93 & 0.44\end{array}$

$88 \quad 57$

0.001

Notes:

${ }^{1}$ Based on survey data. Numbers of public and private universities are 73 and 28 , respectively.

${ }^{2}$ Merit pay and/or bonuses 


\begin{tabular}{lllll}
\hline \hline & \multicolumn{3}{c}{ Public } & \multicolumn{3}{c}{ Pniversities } & \multicolumn{3}{c}{ Private Universities } \\
& $k=2$ & $k=3$ & $k=2$ & $k=3$ \\
Panel A & & & & \\
Own royalty share $\left(\delta_{1}\right)$ & 1.87 & 1.65 & $5.47^{* *}$ & $5.10^{* *}$ \\
& $(1.28)$ & $(1.34)$ & $(2.05)$ & $(2.04)$ \\
Competitors' royalty share $\left(\delta_{2}\right)$ & 2.25 & 0.38 & $-4.55^{* *}$ & $-5.67^{* *}$ \\
& $(3.20)$ & $(4.0)$ & $(1.70)$ & $(2.36)$ \\
$\delta_{1}+\delta_{2}$ & 4.11 & 2.04 & 0.92 & -0.57 \\
& $(3.27)$ & $(4.36)$ & $(2.18)$ & $(3.25)$ \\
$R^{2}$ & 0.61 & 0.61 & 0.71 & 0.71 \\
No. obs & 471 & 471 & 246 & 246 \\
No. Universities & 66 & 66 & 31 & 31 \\
& & & & \\
Panel B & & & & \\
Own royalty share $\left(\delta_{1}\right)$ & 1.59 & 1.39 & $5.96^{* *}$ & $5.84^{* *}$ \\
& $(1.39)$ & $(1.43)$ & $(2.09)$ & $(2.14)$ \\
Competitors' royalty share $\left(\delta_{2}\right)$ & -0.58 & -2.27 & -3.46 & -0.96 \\
& $(2.24)$ & $(2.94)$ & $(4.61)$ & $(3.15)$ \\
$\delta_{1}+\delta_{2}$ & 1.01 & -0.88 & 2.51 & 4.88 \\
$R^{2}$ & $(2.98)$ & $(3.64)$ & $(4.20)$ & $(3.18)$ \\
No. obs & 0.61 & 0.61 & 0.70 & 0.69 \\
No. Universities & 471 & 471 & 246 & 246 \\
\hline & 66 & 66 & 31 & 31 \\
\hline
\end{tabular}

Notes:

Standard errors clustered by university in parentheses. All other control variables appearing in Table 5 included in all regressions but are not reported.

In Panel A competing universities identified by R\&D funding per faculty.

In Panel B competing universities identified by citations per faculty.

${ }^{*}$ Significant at the $5 \%$ level, ${ }^{* *}$ Significant at the $1 \%$ level 
Public Universities

Dep. variable ${ }^{1}$

\author{
Revenues
}

(1)

License

Disclosures

(3)

Private Universities

Log (licenses)

$0.77^{* *}$

Royalty share

$1.65 \quad 1.20$

$(1.53)$

1.20
$(1.55)$

Log faculty size

$1.36^{* *}$

$(1.55)$
-

$(.19)$

Citations/faculty

0.001

(.017)

$\log \left(\frac{R \& D}{\text { faculty }}\right)^{2}$

$0.53^{* *}$

$(.24)$

$\log \left(\frac{T L O}{\text { faculty }}\right)^{2}$

$-0.003 \quad-0.11$

$(.19)$

Age TLO

$(.20)$

$0.024^{* *}$

(.011)

0.006

0.08

(.39)

$0.90^{* *}$

(.096)

0.002

(.015) (.006)

$0.58^{* *} \quad 0.31^{* *}$

(.096)

$0.19^{* *}$

(.094)

$0.012^{* *}$

(.005)

$0.59 \quad 0.61$

0.67

270

270

305

65

65

Notes:

${ }^{1}$ Dependent variables always in logs.

${ }^{2}$ In columns (2) and (6), regressor is not normalized by faculty size

Standard errors clustered by university in parentheses.

Technological fields and year dummies included in all regressions but are not reported.

* Significant at the $5 \%$ level, ${ }^{* *}$ Significant at the $1 \%$ level
(4)

Revenues

Licenses Disclosures

(7)

(8)

$0.77^{* *}$

$(.32)$

$3.83^{* *} \quad 2.60^{* *}$

0.52

$\begin{array}{llll}(.24) \quad(2.22) \quad(1.73) \quad(.96) & 0\end{array}$

$(1.06)$

$1.68^{* *} \quad-\quad 1.20$

$0.85^{*}$

(.21)

(.16)

0.006

$0.008^{* *}$

$0.013^{* *}$

0.007

$0.007^{* *}$

(.004)

$0.38^{* *}$

0.34

0.11

(.003)

$0.48^{* *}$

(.42) (.30)

$0.31^{* *}$

$0.26^{* *}$

$1.11^{* *}$

$0.68^{* *}$

(.11)

$0.23^{*}$

$(.047)$

(.31)

$(.29)$

0.004

(.003)

(.017)

(.012)

0.002

(.007)

(.008)

0.73

250

32 


\begin{tabular}{|c|c|c|c|c|}
\hline & \multicolumn{2}{|c|}{ Private Universities } & \multicolumn{2}{|c|}{ Public Universities } \\
\hline & $\begin{array}{c}\text { w/o Columbia } \& \\
\text { Stanford }\end{array}$ & $\begin{array}{c}\text { Median } \\
\text { Regression }\end{array}$ & w/o California & $\begin{array}{c}\text { Median } \\
\text { Regression }\end{array}$ \\
\hline & $(1)$ & $(2)$ & $(3)$ & $(4)$ \\
\hline Royalty share & $\begin{array}{l}4.72^{* *} \\
(1.92)\end{array}$ & $\begin{array}{c}5.03^{* *} \\
(.81)\end{array}$ & $\begin{array}{c}1.61 \\
(1.35)\end{array}$ & $\begin{array}{c}0.83 \\
(0.48)\end{array}$ \\
\hline Log faculty size & $\begin{array}{c}1.40^{* *} \\
(.24)\end{array}$ & $\begin{array}{c}1.50^{* *} \\
(.11)\end{array}$ & $\begin{array}{c}1.39^{* *} \\
(.19)\end{array}$ & $\begin{array}{l}1.49^{* *} \\
(.083)\end{array}$ \\
\hline Citations/faculty & $\begin{array}{c}0.015^{* *} \\
(.006)\end{array}$ & $\begin{array}{c}0.018^{* *} \\
(.003)\end{array}$ & $\begin{array}{l}0.008 \\
(.014)\end{array}$ & $\begin{array}{c}0.025^{* *} \\
(.007)\end{array}$ \\
\hline $\log (R \mathscr{E} D /$ faculty $)$ & $\begin{array}{l}0.46 \\
(.33)\end{array}$ & $\begin{array}{c}0.127 \\
(.13)\end{array}$ & $\begin{array}{c}0.48^{* *} \\
(.20)\end{array}$ & $\begin{array}{c}0.42^{* *} \\
(.12)\end{array}$ \\
\hline $\log (T L O /$ faculty $)$ & $\begin{array}{l}0.56^{*} \\
(.30)\end{array}$ & $\begin{array}{c}0.831^{* *} \\
(.11)\end{array}$ & $\begin{array}{c}-0.020 \\
(.17)\end{array}$ & $\begin{array}{l}0.153^{*} \\
(.091)\end{array}$ \\
\hline Age TLO & $\begin{array}{l}0.017 \\
(.013)\end{array}$ & $\begin{array}{l}0.007 \\
(.008)\end{array}$ & $\begin{array}{c}0.025^{* *} \\
(.010)\end{array}$ & $\begin{array}{c}0.026^{* *} \\
(.005)\end{array}$ \\
\hline$R^{2}$ & 0.65 & 0.48 & 0.56 & 0.40 \\
\hline No. obs. & 228 & 246 & 462 & 471 \\
\hline No. Universities & 29 & 31 & 65 & 66 \\
\hline
\end{tabular}

Notes:

Standard errors clustered by university in parentheses in the OLS regressions (1) and (3). Non-robust standard errors in the median regressions (2) and (4).

Technological fields and year dummies included in all regressions but are not reported.

* Significant at the $5 \%$ level, ${ }^{* *}$ Significant at the $1 \%$ level 


\begin{tabular}{|c|c|c|c|c|c|c|c|c|}
\hline & \multicolumn{4}{|c|}{ Private Universities } & \multicolumn{4}{|c|}{ Public Universities } \\
\hline & $(1)$ & $(2)$ & $(3)$ & $(4)$ & $(5)$ & $(6)$ & $(7)$ & $(8)$ \\
\hline Royalty share & $\begin{array}{l}4.69^{* *} \\
(2.10)\end{array}$ & $\begin{array}{c}3.76 \\
(2.10)\end{array}$ & $\begin{array}{c}3.84^{* *} \\
(1.93)\end{array}$ & $\begin{array}{l}4.68^{* *} \\
(2.24)\end{array}$ & $\begin{array}{l}1.67 \\
(1.33)\end{array}$ & $\begin{array}{l}1.67 \\
(1.33)\end{array}$ & $\begin{array}{l}1.75 \\
(1.34)\end{array}$ & $\begin{array}{l}1.65 \\
(1.37)\end{array}$ \\
\hline Log faculty size & $\begin{array}{c}1.19^{* *} \\
(.36)\end{array}$ & $\begin{array}{c}0.99^{* *} \\
(.42)\end{array}$ & $\begin{array}{c}1.03^{* *} \\
(.37)\end{array}$ & $\begin{array}{l}1.07^{*} \\
(.56)\end{array}$ & $\begin{array}{l}1.40^{* *} \\
(.18)\end{array}$ & $\begin{array}{c}1.45^{* *} \\
(.23)\end{array}$ & $\begin{array}{c}1.37^{* *} \\
(.17)\end{array}$ & $\begin{array}{c}1.52^{* *} \\
(.27)\end{array}$ \\
\hline Publications/faculty & $\begin{array}{l}0.19^{* *} \\
(.069)\end{array}$ & - & - & $\begin{array}{c}-0.032 \\
(.12)\end{array}$ & $\begin{array}{l}0.006 \\
(.068)\end{array}$ & - & - & $\begin{array}{c}-0.037 \\
(.11)\end{array}$ \\
\hline NRC quality score & - & $\begin{array}{c}1.05^{* *} \\
(.41)\end{array}$ & - & $\begin{array}{l}0.57 \\
(.66)\end{array}$ & - & $\begin{array}{c}-0.068 \\
(.35)\end{array}$ & - & $\begin{array}{c}-0.174 \\
(.45)\end{array}$ \\
\hline Log (Average Salary) & - & - & $\begin{array}{l}4.95^{* *} \\
(1.75)\end{array}$ & $\begin{array}{l}1.91 \\
(2.28)\end{array}$ & - & - & $\begin{array}{c}0.55 \\
(1.33)\end{array}$ & $\begin{array}{c}0.51 \\
(1.33)\end{array}$ \\
\hline Citations per faculty & - & - & - & $\begin{array}{l}0.011 \\
(0.010)\end{array}$ & - & - & - & $\begin{array}{l}0.016 \\
(.022)\end{array}$ \\
\hline $\log (R \mathscr{E} D /$ faculty $)$ & $\begin{array}{l}0.32 \\
(.35)\end{array}$ & $\begin{array}{l}0.49 \\
(.33)\end{array}$ & $\begin{array}{l}0.14 \\
(.27)\end{array}$ & $\begin{array}{l}0.13 \\
(.24)\end{array}$ & $\begin{array}{c}0.51^{* *} \\
(.20)\end{array}$ & $\begin{array}{c}0.54^{* *} \\
(.25)\end{array}$ & $\begin{array}{c}0.49^{* *} \\
(.20)\end{array}$ & $\begin{array}{c}0.53^{* *} \\
(.27)\end{array}$ \\
\hline Log (TLO/faculty) & $\begin{array}{c}0.89^{* *} \\
(.32)\end{array}$ & $\begin{array}{c}0.82^{* *} \\
(.34)\end{array}$ & $\begin{array}{c}0.83^{* *} \\
(.33)\end{array}$ & $\begin{array}{c}0.77^{* *} \\
(.32)\end{array}$ & $\begin{array}{c}-0.010 \\
(.16)\end{array}$ & $\begin{array}{c}-0.007 \\
(.16)\end{array}$ & $\begin{array}{c}-0.027 \\
(.16)\end{array}$ & $\begin{array}{c}-0.015 \\
(.16)\end{array}$ \\
\hline Age TLO & $\begin{array}{l}0.014 \\
(.019)\end{array}$ & $\begin{array}{l}0.002 \\
(.019)\end{array}$ & $\begin{array}{c}0.019 \\
(0.021)\end{array}$ & $\begin{array}{l}0.007 \\
(.018)\end{array}$ & $\begin{array}{c}0.026^{* *} \\
(.010)\end{array}$ & $\begin{array}{c}0.026^{* *} \\
(.010)\end{array}$ & $\begin{array}{c}0.026^{* *} \\
(.010)\end{array}$ & $\begin{array}{c}0.026^{* *} \\
(.010)\end{array}$ \\
\hline $\begin{array}{l}\text { F- test for quality effe } \\
\text { p-value }\end{array}$ & & & & $<0.001$ & & & & 0.91 \\
\hline$R^{2}$ & 0.68 & 0.69 & 0.69 & 0.72 & 0.61 & 0.61 & 0.61 & 0.61 \\
\hline No. obs. & 246 & 246 & 245 & 245 & 471 & 471 & 471 & 471 \\
\hline No. Universities & 31 & 31 & 30 & 30 & 66 & 66 & 66 & 66 \\
\hline
\end{tabular}

Notes:

Standard errors clustered by university in parentheses. Missing wage data for one private university appearing in one year only. Technological fields and year dummies included in all regressions but are not reported. ${ }^{*}$ Significant at the $5 \%$ level, ${ }^{* *}$ Significant at the $1 \%$ level 
Public Universities

Private Universities

\begin{tabular}{|c|c|c|c|c|}
\hline & \multicolumn{4}{|c|}{ Royalty share interacted with: } \\
\hline & $\begin{array}{l}\text { Quality } \\
\text { quartiles }\end{array}$ & $\begin{array}{l}\text { Tenure } \\
\text { quartiles }\end{array}$ & $\begin{array}{c}\text { Quality } \\
\text { quartiles }\end{array}$ & $\begin{array}{l}\text { Tenure } \\
\text { quartiles }\end{array}$ \\
\hline $\begin{array}{l}\text { Royalty share } \\
\left(2^{\text {nd }} \mathscr{E} 3^{\text {rd }} \text { quartiles }\right)\end{array}$ & $\begin{array}{c}1.30 \\
(1.03)\end{array}$ & $\begin{array}{l}1.08 \\
(1.21)\end{array}$ & $\begin{array}{c}3.46 \\
(2.05)\end{array}$ & $\begin{array}{l}4.46^{* *} \\
(1.68)\end{array}$ \\
\hline $\begin{array}{l}\text { Royalty share } \times \\
1^{\text {st }} \text { quartile dummy }\end{array}$ & $\begin{array}{l}2.10^{*} \\
(1.10)\end{array}$ & $\begin{array}{l}0.60 \\
(.91)\end{array}$ & $\begin{array}{l}3.17^{* *} \\
(1.28)\end{array}$ & $\begin{array}{c}1.78^{* *} \\
(.76)\end{array}$ \\
\hline $\begin{array}{l}\text { Royalty share } \times \\
4^{\text {st }} \text { quartile dummy }\end{array}$ & $\begin{array}{l}0.30 \\
(.89)\end{array}$ & $\begin{array}{c}1.46^{* *} \\
(.75)\end{array}$ & $\begin{array}{l}1.31 \\
(.86)\end{array}$ & $\begin{array}{l}-0.517 \\
(1.05)\end{array}$ \\
\hline Log faculty size & $\begin{array}{c}1.53^{* *} \\
(.17)\end{array}$ & $\begin{array}{c}1.44^{* *} \\
(.18)\end{array}$ & $\begin{array}{c}1.74^{* *} \\
(.27)\end{array}$ & $\begin{array}{c}1.51^{* *} \\
(.22)\end{array}$ \\
\hline Citations/faculty & $\begin{array}{l}0.028 \\
(.024)\end{array}$ & $\begin{array}{l}0.003 \\
(.015)\end{array}$ & $\begin{array}{c}0.018^{* *} \\
(.005)\end{array}$ & $\begin{array}{c}0.017^{* *} \\
(.007)\end{array}$ \\
\hline $\log (R \mathscr{E} D /$ faculty $)$ & $\begin{array}{c}0.38^{*} \\
(.21)\end{array}$ & $\begin{array}{c}0.55^{* *} \\
(.20)\end{array}$ & $\begin{array}{l}0.19 \\
(.33)\end{array}$ & $\begin{array}{l}0.27 \\
(.37)\end{array}$ \\
\hline $\log (T L O /$ faculty $)$ & $\begin{array}{c}0.006 \\
(.16)\end{array}$ & $\begin{array}{c}0.007 \\
(.16)\end{array}$ & $\begin{array}{l}.50 \\
(.32)\end{array}$ & $\begin{array}{c}0.54^{* *} \\
(.26)\end{array}$ \\
\hline Age TLO & $\begin{array}{c}0.028^{* *} \\
(.010)\end{array}$ & $\begin{array}{c}0.025^{* *} \\
(.009)\end{array}$ & $\begin{array}{l}0.014 \\
(.020)\end{array}$ & $\begin{array}{l}0.018 \\
(.017)\end{array}$ \\
\hline$R^{2}$ & 0.63 & 0.63 & 0.73 & 0.73 \\
\hline No. obs & 471 & 471 & 246 & 246 \\
\hline No. Universities & 66 & 66 & 31 & 31 \\
\hline
\end{tabular}

Notes:

Standard errors clustered by university in parentheses.

Technological fields and year dummies included in all regressions but are not reported.

* Significant at the $5 \%$ level, ${ }^{* *}$ Significant at the $1 \%$ level 


\begin{tabular}{lcc}
\hline \hline & & \\
Royalty share & & \\
& $(1.32)$ & Private Universities \\
Log faculty size & $1.40^{* *}$ & $\left(2.163^{* *}\right.$ \\
& $(.17)$ & $1.57^{* *}$ \\
Citations/faculty & 0.010 & $(.28)$ \\
& $(.014)$ & $0.018^{* *}$ \\
Log (public REDD/faculty) & $0.45^{* *}$ & $(.005)$ \\
& $(.21)$ & 0.38 \\
Log (private R\&D/faculty) & -0.052 & $(.32)$ \\
& $(.14)$ & -0.046 \\
Log (TLO/faculty) & -0.009 & $(.19)$ \\
& $(.16)$ & $.789^{* *}$ \\
Age TLO & $0.022^{* *}$ & $(.31)$ \\
& $(.010)$ & 0.011 \\
F-test for equal REDD effects & & $(.017)$ \\
p-value & & \\
$R^{2}$ & 0.094 & 0.325 \\
No. obs & & \\
No. Universities & 0.61 & 0.70 \\
\hline
\end{tabular}

Notes:

Standard errors clustered by university in parentheses.

Technological fields and year dummies included in all regressions but are not reported.

${ }^{*}$ Significant at the $5 \%$ level, ${ }^{* *}$ Significant at the $1 \%$ level 


\begin{tabular}{lcc}
\hline \hline & Public Universities & Private Universities \\
& & \\
$1^{\text {st }}$ quartile dummy & 0.50 & -0.085 \\
& $(1.32)$ & $(1.96)$ \\
$4^{\text {st }}$ quartile dummy & -0.089 & $3.11^{* *}$ \\
& $(1.20)$ & $(1.06)$ \\
Royalty share (in $2^{\text {nd }} \& 3^{\text {rd }}$ quartiles) & 2.10 & $10.32^{* *}$ \\
& $(2.31)$ & $(1.76)$ \\
Royalty share $\times 1^{\text {st }}$ quartile dummy & -0.096 & 1.63 \\
& $(2.93)$ & $(3.81)$ \\
Royalty share $\times 4^{\text {st }}$ quartile dummy & 0.78 & $-6.57^{* *}$ \\
& $(2.28)$ & $(2.92)$ \\
Log faculty size & $1.37^{* *}$ & $1.82^{* *}$ \\
& $(.19)$ & $(.31)$ \\
Citations/faculty & 0.009 & $0.016^{* *}$ \\
& $(.014)$ & $(.005)$ \\
Log $($ RED/faculty) & $0.55^{* *}$ & 0.46 \\
& $(.24)$ & $(.29)$ \\
Log (TLO/faculty) & -0.061 & $.85^{* *}$ \\
Age TLO & $(.16)$ & $(.29)$ \\
& $0.028^{* *}$ & 0.003 \\
$R^{2}$ & $(.011)$ & $(.019)$ \\
No. obs Universities & & 0.72 \\
\hline
\end{tabular}

Notes:

Standard errors clustered by university in parentheses.

Technological fields and year dummies included in all regressions but are not reported.

${ }^{*}$ Significant at the $5 \%$ level, ${ }^{* *}$ Significant at the $1 \%$ level 


\section{References}

[1] Adams, James (1990), "Fundamental Stocks of Knowledge and Productivity Growth," Journal of Political Economy, 98(4), 673-702.

[2] Adams, James (2002), "Comparative Localization of Academic and Industrial Spillovers", Journal of Economic Geography, vol. 2, 253-278.

[3] Adams, James and Zvi Griliches (1998), "Research Productivity in a System of Universities," Annales D'Economie et de Statistique, No. 49/50.

[4] Association of University Technology Managers (2000), AUTM Licensing Survey

[5] Audretsch, David and Paula Stephan (1996), "Company-Scientist Locational Links: The Case of Biotechnology," American Economic Review, 86(3), 641-652.

[6] Davidson Russell, and James G. MacKinnon (1993) Estimation and Inference in Econometrics (Oxford: Oxford University Press)

[7] Friedman, Joseph and Jonathan Silberman (2003), "University Technology Transfer: Do Incentives, Management and Location Matter?" Journal of Technology Transfer, 28 (1), $17-30$.

[8] Goldberger, Marvin, Brendan A. Maher, and Pamela Ebert Flattau, eds., ResearchDoctorate Programs in the United States: Continuity and Change, National Academy Press, Washington DC, 1995.

[9] Henderson, Rachel, Adam Jaffe and Manuel Trajtenberg (1998), "Universities as a Source of Commercial Technology: A Detailed Analysis of University Patenting, 1965-1988," Review of Economics and Statistics, 119-127.

[10] Jaffe, Adam (1989), "Real Effects of Academic Research," American Economic Review, $79(5), 957-970$

[11] Jaffe, Adam and Manuel Trajtenberg (2002), Patents, Citations $\&$ Innovations: A Window on the Knowledge Economy (Cambridge: MIT Press) 
[12] Jaffe, Adam, Manuel Trajtenberg and Rebecca Henderson (1993), "Geographic Localization of Knowledge Spillovers as Evidenced by Patent Citations," Quarterly Journal of Economics, 108(3), 577-598.

[13] Jensen, Richard and Marie Thursby (2001), "Proofs and Prototypes for Sale: The Licensing of University Inventions," American Economic Review, 91(1), 240-259.

[14] Lazear, Edward (2000), "Performance Pay and Productivity," American Economic Review, 90(5), 1346-1361

[15] Lazear, Edward P. "Incentives in Basic Research", Journal of Labor Economics,1997, vol.15, no.1, pt.2, 167-196.

[16] Macho-Stadler, Ines, David Perez-Castrillo and Reinhilde Veugelers "Licensing of University Innovations: The Role of a Technology Transfer Office", mimeo 2004.

[17] National Science Board (2000), Science and Engineering Indicators (Washington D.C.: National Science Foundation).

[18] Payne, A. Abigail and Aloysius Siow (2003), "Does Federal Research Funding Increase University Research Output?", Advances in Economic Analysis 83 Policy, Volume 3, Issue 1.

[19] Schankerman, Mark (1998), "How Valuable is Patent Protection? Estimates by Technology Field," RAND Journal of Economics, 29(1), 77-107.

[20] Siegel, Donald, David Waldman and Albert Link (2003), "Assessing the Impact of Organizational Practices on the Relative Productivity of University Technology Transfer Offices: An Exploratory Study", Research Policy, 32(1), 27-48.

[21] Thursby, Jerry and S. Kemp (2002), "Growth and Productive Efficiency of University Intellectual Property Licensing," Research Policy, 31(1), 109-124.

[22] Tuomala, Matti (1990), Optimal Income Tax and Redistribution (Clarendon Press: Oxford). 


\section{Appendix}

\section{A Description of the Data}

\section{A.1 Variable Definitions}

\section{Data from AUTM Licensing Surveys 1991-99.}

1. Licensing income includes license issue fees, payments under options, annual minimums, running royalties, termination payments, the amount of equity received when cashed-in, and software and biological material end-user license fees equal to $\$ 1,000$ or more. License income includes net transfers of license income from other institutions.

2. TLO Size is the number of person(s) employed in the $T L O$ whose duties are specifically involved with the licensing and patenting processes in either full or fractional allocation. Licensing examples include licensee solicitation, technology valuation, marketing of technology, license agreement drafting and negotiation, and start-up activity efforts. Because this information is not available for 1991, we used the data for 1992 to measure size in 1991. The change in the point estimates is minimal but their precision increases due to the larger number of observations.

3. TLO Age is measured using the year when then TLO was established as reported by the AUTM surveys. When the foundation year was on 1991 or later we recoded the foundation year to be the first year when the TLO size was larger than 0.5-one half full-time equivalent professional employed.

4. RED funding includes the total amount of research support committed to the university (even if the funds are to be spent over several years) that was related to license/options agreements.

\section{Data from the 1993 National Survey of Graduate Faculty}

The Survey provides data on doctoral programs that participated in the 1993 National Research Council (NRC) National Survey of Graduate Faculty (appendix K on engineering programs, appendix L on life science programs, and appendix $\mathrm{N}$ on biological sciences). 
1. Science Fields: 23 doctoral programs were aggregated into 6 science fields. We used the shares of faculty employed in each field to proxy for the research orientation of the university. The fields are:

(a) Biomedical and Genetics - biochemical/molecular biology, cell and development biology, biomedical engineering and molecular and general genetics

(b) Other Biological Sciences - neurosciences, pharmacology, physiology and ecology/evolution and behavior

(c) Computer Science includes only the department of computer sciences

(d) Chemical Science - chemistry and chemical engineering

(e) Engineering - aerospace, civil engineering, electrical engineering, industrial engineering, material science, and mechanical engineering

(f) Physical Sciences - astrophysics/astronomy, geosciences, mathematics, oceanography, physics, and statistics/biomedical statistics.

2. Faculty Size is the total number of faculty in the 23 doctoral programs as reported in the Survey.

3. Quality measures:

(a) Citations per faculty: ratio of total number of program citations in the period 198892 to the number of program faculty. Aggregated to the university level using faculty weights.

(b) Publications per faculty: ratio of total number of program publications in the period 1988-92 to the number of program faculty. Aggregated to the university level using faculty weights.

(c) Scholarly quality index of program faculty is the trimmed mean of the responses received in the Survey for each doctoral program. Scores were converted to a scale of 0 to 5 , with 0 denoting "Not sufficient for doctoral education" and 5 denoting five "Distinguished". Aggregated to the university level using faculty weights. 
In some instances, a university appears more than once in the NRC file because the NRC has information on two or even three units of the same department, e.g., statistics and biostatistics or meteorology and geology (in geosciences). In these instances we averaged their quality measures weighting each unit by its share in the total faculty number of both units combined. In other instances, a university appears more than once in the NRC file because the NRC has information on two or more campuses (e.g., California, Rutgers, etc.). In these instances we averaged their quality measures weighting each campus by its share in the total faculty number of all campuses combined.

\section{Data from TLO's Websites}

1. Inventor's royalty share: This information was downloaded from the websites of each university technology licensing offices during the summer of 2001. The net income received by the university from licensing an invention is distributed between the inventor and the university. The university allocates its share to various units such as the inventor's laboratory, department or college. The criterion we use for identifying the inventor share is that the inventor must gain either cash flow rights or direct control rights over the income. Thus, when the university IP policy states that the share accruing to the lab was under the control of the inventor, we added it to the inventor's share, but otherwise we did not. Royalty shares were computed out of net license income after deducting direct licensing expenses from gross income. We also made an adjustment for the TLO's overhead rate, when it was reported.

\section{Other Data}

1. Average Salary at the university level, i.e., not just hard science departments. Source: NSF WebCASPAR Database System.(http://caspar.nsf.gov/webcaspar).

2. Percentage of Tenured Faculty at the university level, i.e., not just hard science departments. Source: NSF WebCASPAR Database System.(http://caspar.nsf.gov/webcaspar).

3. Milken Institute Tech-Pole composite index 


\section{A.2 Data Selection Process}

1. Starting with the nine files containing the Association of University Technology Managers' (AUTM) Annual Licensing Surveys for 1991-99 we compiled a list of 209 institutions with licensing income and disclosure data for all or part of the 1991-99 period. These institutions include American and Canadian universities, medical research institutes and patent management firms.

2. The size and quality measures from the 1993 National Survey of Graduate Faculty conducted by the National Research Council (NRC) are available for universities with doctoral programs only. This reduces the sample of institutions with AUTM and NRC data to 146 .

3. Merging with the royalty share distribution data further reduced the number of institutions with AUTM, NRC and royalty share data to 102. Most teaching hospitals and patent management firms do not post royalty distribution information on the internet.

Since all but one (Albert Einstein Healthwork Network) of these institutions are universities, we refer to the observations as universities.

\section{A.3 Structure of the Data}

We have an panel data on 102 universities with non-missing license income data ranging from $T=1$ to $T=9$ years. The distribution of universities with $T=t$ is given in the second column of the Table below, 
Distribution of Panel Time Length

\begin{tabular}{lccc}
\hline \hline & & Overall & Baseline Regression \\
& $T$ & Frequency & Frequency \\
& 1 & 3 & 1 \\
2 & 2 & 2 \\
3 & 3 & 5 \\
4 & 7 & 3 \\
& 5 & 5 & 6 \\
& 6 & 11 & 12 \\
& 7 & 10 & 11 \\
& 8 & 5 & 7 \\
Total & 9 & 56 & 51 \\
Number of Observations & 749 & \\
\hline
\end{tabular}

This gives a total of 749 university-year observations with non-missing license income data. Tables 1-4 rely on the full sample of 102 universities but the sample used in Tables 5 -13 is smaller because of missing variables and observations with zero license income (we use the log of license income). There are 18 observations with zero license income. Eight of these observations, belong to four universities not having any non-zero license data. Thus, they are excluded from the baseline sample used in the regressions. The remaining 10 observations belong to 4 institutions having other non-zero license data so they remain in the baseline regression sample. In particualr, the "short" specifications in columns (1), (3) and (5) of Table 5 are based on 98 universities (102 - 4 universities with all their license data equal to zero). Assigning a zero value to the dependent variable of the universities with zero license revenue, and including them in the regression, did not change the parameter estimates.

Other control variables are also missing. Three universities have missing information on the TLO foundation year so that the TLO age cannot be computed. Because two of these also have zero license income data, we only have to drop 4 observations (and one university) on account of missing TLO age from the baseline regression sample. In addition nine observations, corresponding to 5 universities, have missing TLO size data and one observation has missing data on R\&D funding. These 10 observations, but not the universities, are dropped from the baseline regression sample.

To summarise, a total of 32 observations and 5 universities are dropped from the baseline regression sample because of zero licence income or other missing data. This leaves 717 
observations in 97 universities used in the "long" specifications in Table 5, columns (2), (4) and (6). The distribution of universities with different numbers of observations in the baseline regression samples is given in the third column of the table. 